\title{
EVOLUÇÃO DA PRODUTIVIDADE E AJUSTES PRODUTIVOS NA INDÚSTRIA BRASILEIRA NO PERÍODO 1996-2013: UMA ABORDAGEM INTER-SETORIAL A PARTIR DOS DADOS DA PIA-IBGE
}

\section{Introdução}

Jorge Nogueira de Paiva Britto

O estudo discute os a trajetória evolutiva recente da produtividade da indústria brasileira, utilizando como base informações extraídas da PIA-IBGE para o período 1996-2013, incorporando um recorte setorial abrangente que distingue 26 setores, que se aproximam da classificação a dois dígitos da CNAE. A análise dessa trajetória insere-se no debate sobre os fatores que explicariam o baixo dinamismo da indústria brasileira no período recente, que tem se intensificado nos últimos anos. Uma análise acurada dessas transformações pode encontrar evidências de fontes de dinamismo, mesmo num contexto geral adverso, que seriam capazes de favorecer a retomada do crescimento da indústria em bases mais sustentáveis. Esse artigo apresenta evidências empíricas que podem subsidiar esse debate, a partir de um enfoque de tradição estruturalista, para um período relativamente longo, entre 1996-2013, ao longo do qual ocorreram transformações importantes no cenário interno e externo, com reflexos importantes na dinâmica de transformação produtiva e no desempenho da indústria brasileira.

A análise elaborada procura estabelecer um diálogo com os principais argumentos do debate sobre a trajetória evolutiva recente da indústria brasileira. Com este intuito, o artigo estrutura-se em quatro seções. A primeira seção apresenta os principais argumentos da literatura referentes á evolução recente da produtividade da indústria no caso brasileiro. A segunda seção apresenta a metodologia de análise em termos dos indicadores, periodização, recorte setorial e procedimentos de análise dos dados extraídos da PIA para o período 1996-2013. A terceira seção desenvolve uma análise geral da evolução da produtividade da indústria, considerando tanto o conjunto do período, como diferentes subperíodos trienais, articulando essa evolução a outras evidências de ajuste produtivo extraídas de dados da PIA. A quarta seção procura qualificar melhor as tendências identificadas, articulando-as à conformação e à dinâmica evolutiva da estrutura setorial da indústria. Uma seção conclusiva busca identificar, a partir da análise realizada, possíveis fatores que operam com fontes de dinamismo da estrutura industrial brasileira, discutindo desdobramentos sobre uma possível retomada da sua trajetória de crescimento.

\section{1 - A evolução recente da produtividade da indústria: argumentos da literatura}

Diversas análises sobre a trajetória recente da indústria brasileira, elaboradas a partir de diferentes fundamentações teóricas, apresentam um foco centrado na evolução da produtividade da indústria, e particularmente no seu baixo dinamismo comparativamente a outras atividades. Neste sentido, Negri e Cavalcanti (2014) ressaltam que os trabalhos que analisam o comportamento da produtividade no Brasil no período recente nem sempre chegam a resultados idênticos, em razão das diferentes medidas de produtividade que são empregadas e de diferentes fontes de dados e períodos específicos de análise. Quanto aos indicadores de produtividade, eles idealmente procurariam medir, de algum modo, a eficiência associada à transformação de insumos em produtos e serviços finais, utilizando medidas de produção e medidas de insumos, seja através de medidas parciais, como a produtividade do trabalho ou do capital, de medidas multifatores, como a Produtividade Total dos Fatores (PTF), ou ainda utilizando medidas baseadas em fronteiras de produção, entre outras. As medidas parciais de produtividade do trabalho usualmente ignoram tanto a intensidade, quanto a qualidade do capital utilizado na produção, assim como a qualidade do trabalho (ou o capital humano). Além disso, existiriam problemas relacionados à mensuração do produto e da quantidade de trabalho. No caso do produto, é possível utilizar indicadores de produção física ou indicadores monetários de valor adicionado. No primeiro caso, existem problemas decorrentes da necessidade de considerar múltiplos produtos e múltiplos insumos, o que faz com que se privilegie usualmente a utilização de dados sobre o produto final, sem descontar os insumos utilizados. Já os indicadores monetários de valor adicionado são mais precisos para mensurar eficiência, mas tendem a ser afetados por variações de preços relativos que não expressam necessariamente uma maior eficiência. 
A partir dessas qualificações, diversas análise procuram avançar na análise da evolução da produtividade da indústria brasileira nas últimas décadas, de modo a qualificar melhor o fenômeno da desindustrialização. Pauli, Nakabashi e Sampaio (2012) apontam que, após a exacerbada aceleração da produtividade da indústria entre 1990 e 1999, ocorreu uma estabilização relativa a partir dos anos 2000, após o fim do choque da abertura comercial. Esse processo, no entanto, teria ocorrido sem um aumento na demanda por trabalhadores qualificados na indústria, resultando numa queda nos salários médios. Ferreira, Ellery Junior e Gomes (2008) e Sampaio, Porcile e Curado (2005) também apontam para a inversão na evolução da produtividade no Brasil a partir dos anos 90, que vinha caindo desde os anos 70. Bonelli e Fontes (2013), apontam para uma queda de 0,9\% a.a da produtividade do trabalho na década de 80, com reversão na década de 90 e crescimento modesto de $0,7 \%$ a.a, enquanto, entre 2000 e 2012, esta taxa teria evoluído para uma média positiva de 1,2\% a.a., refletindo o comportamento estimado da PTF. Segundo Bonelli (2011), a desaceleração da produção no final da década, acompanhada da desvalorização cambial a partir de 1999, implicaram redução no ritmo de aumento da produtividade, tanto do total dos fatores quanto do trabalho, o que reforçaria as evidências sobre o caráter pró-cíclico da produtividade. Segundo Nassif, Feijó e Araújo (2014), no período 2000-2008, enquanto a taxa de crescimento do PIB real foi de 3,72\% a.a., a produtividade do trabalho teve variação negativa de $-0,95 \%$ a.a. A análise desses autores fundamenta-se nos argumentos da Lei de Kaldor- Verdoorn, segundo a qual as taxas de incremento da produtividade do trabalho seriam consequência da evolução das taxas de crescimento econômico do país, procurando elaborar exercícios econométricos que demonstram que a taxa de variação do PIB real foi a variável mais significativa para explicar o comportamento da produtividade do trabalho na indústria brasileira.

Negri e Cavalcante (2014), em uma síntese de trabalhos sobre o tema, apontam que a maioria dos mesmos identifica um crescimento mais acelerado da PTF na década de 2000 (sobretudo após 2003) do que na década de 1990, o que seria compatível com o crescimento econômico observado no país até a crise, evidenciando o caráter pró-cíclico do indicador. Além disso, as estimativas da PTF que não utilizam capital humano apontam resultados mais positivos nos anos 2000 do que aquelas que incluem capital humano. Qualificando melhor essa evolução, Bonelli e Bacha (2013) reportaram um crescimento médio anual da produtividade do trabalho da ordem de $0,67 \%$, no período entre 2000 e 2009 , enquanto Bonelli e Veloso (2012), cuja análise é restrita ao período entre 2003 e 2009, obtiveram uma taxa média anual de crescimento da produtividade de 1,2\%. Atualizando essas informações, Bonelli (2014) estima que a produtividade do trabalho cresceu a uma taxa média anual de 2,1\%, entre 2002 e 2013; porém, no período mais recente, ao comparar-se os triênios 2008-2010 e 2011-2013, conclui-se que a queda da produtividade do trabalho (de 2,5\% a.a. para 1,9\% a.a.) explica quase um terço da queda do PIB.

Com foco mais direcionado para a evolução da produtividade da indústria, a análise de Feijó e Carvalho (2005) mostra que a evolução da produtividade do trabalho medida pela relação entre Produção Física e Pessoal Ocupado, captados através da PIM-PF e da PIMES, apresenta crescimento na década de 1970, estagnação e regressão na década de 1980, retomada de crescimento nos anos 1990 e recuperação a partir de 2002, principalmente em 2004. Dando continuidade à análise, Galeano e Feijó (2013) investigam a produtividade do trabalho (medida pela relação VTI/PO) na PIA de 1996 a 2007, concluindo pela perda de crescimento da produtividade no período, identificando um descenso a partir de 2000 e revendo as estimativas de crescimento depois de 2004. Squeff et al. (2012) avaliam a evolução da produtividade do trabalho da indústria (medida pela relação VA/PO) no período 2000-2009 com base em dados das Contas Nacionais, concluindo por uma lenta e paulatina queda da produtividade do trabalho, em termos médios, de $-0,6 \%$ a.a. na indústria como um todo e de $-0,9 \%$ a.a. na indústria de transformação, apesar do crescimento da produtividade do trabalho de cerca de $0,9 \%$ a.a. para o conjunto da economia no mesmo período.

Negri e Cavalcante (2014) ressaltam que a trajetória da produtividade é sensivelmente afetada pela escolha do deflator. Especificamente no tocante ao período 1996-2011, ao se deflacionar o VTI usando o índice de preços no atacado (IPA) setorial, verifica-se que a produtividade exibe, em geral, uma tendência descendente ao longo do período, com uma taxa média de crescimento negativa $(-1,0 \%)$ entre 2000 e 2011. Já escolha de um deflator baseado no IPA agregado (IPA-EP) leva a uma trajetória um pouco diferente. O uso de um deflator mais geral (nesse caso, o deflator implícito do PIB) indica uma tendência 
ascendente entre 1996 e 2004 e, daí em diante, uma tendência de queda, com uma taxa média de crescimento ajustada da produtividade entre 2000 e 2011 de $-1,2 \%$. Já quando se usa o Índice Nacional de Preços ao Consumidor Amplo (IPCA) para deflacionar a produtividade do trabalho da indústria de transformação, observa-se um comportamento distinto da variável, que se apresentaria ascendente até 2004, a partir de quando parece estabilizar-se, resultando numa taxa de crescimento ajustada positiva da ordem de $0,5 \%$ entre 2000 e 2011.

Apesar da diversidade de conceitos, formas de mensuração e fonte de dados, Negri e Cavalcante (2014) constatam que os estudos sobre o crescimento da produtividade na economia brasileira indicam que esse crescimento tem sido menor do que o necessário para sustentar o crescimento de longo prazo. Mesmo em períodos de maior crescimento econômico, a produtividade - parcial ou total - não cresceu mais do que $2 \%$ ao ano, como no caso do período 2003-2008. O baixo desempenho da produtividade aparentemente é uma característica estrutural da economia brasileira, que se mantém desde o final dos anos 70, não parecendo estar relacionada a uma conjuntura ou período específico, mas, a causas mais profundas e complexas do que meramente conjunturais. Para identificar essas causas, muitas análises apontam para a relevância de um foco nas características da estrutura produtiva e, em particular, no processo de "mudança estrutural". Se, por um lado, essa "mudança estrutural" explicaria o crescimento acelerado da economia (e da produtividade) brasileira até os anos 70, por outro lado, seria importante investigar se a produtividade parou de crescer em virtude do esgotamento do processo de mudança estrutural e se eventuais mudanças na estrutura produtiva teriam, atualmente, um papel relevante sobre o desempenho da produtividade agregada. No entanto, a análise de Miguez e Moraes (2014) indica que as mudanças na estrutura produtiva teriam efeitos limitados na evolução dos indicadores de produtividade agregada, demonstrando que, mesmo que o Brasil tivesse uma estrutura setorial igual à de alguns países avançados, seus ganhos de produtividade não seriam tão grandes quanto se o país ampliasse a produtividade dentro de cada setor de atividade. Squeff e de Negri (2014) analisam mais detidamente a relação entre mudança estrutural e produtividade nos anos 2000, a partir de técnicas de decomposição "shift-share", concluindo que, durante a década de 2000, os movimentos de mudança estrutural foram relativamente sutis, alguns deles contribuindo positivamente e outros negativamente para a produtividade agregada. No balanço geral dos autores, o efeito da mudança estrutural sobre o modesto crescimento da produtividade agregada foi positivo, tanto no período 2001-2009, quanto no período 2009-2012. Neste último período, seria de se esperar um efeito negativo, dada a forte redução da participação da indústria nas ocupações, mas essa redução provavelmente foi mais do que compensada pela continuidade do processo de redução da participação das ocupações agrícolas nas ocupações totais.

Squeff e Araujo (2013) associam a evolução da produtividade à discussão da heterogeneidade estrutural da indústria brasileira, a partir da estimação de modelos de curto e de longo prazo para 16 setores industriais. Essa análise pressupõe que, para reduzir a heterogeneidade estrutural e viabilizar uma convergência produtiva, é necessário que, durante algum período de tempo, a produtividade dos setores de baixa produtividade cresça a taxas superiores à média geral. Nos modelos estimados, a produtividade do trabalho, variável-chave para a discussão da heterogeneidade estrutural, foi regredida contra a taxa de câmbio, exportações e importações. Os coeficientes estimados evidenciaram que o efeito da taxa de câmbio sobre a produtividade do trabalho é distinto, em sinal e magnitude, entre os diversos setores industriais. Comparando os setores de menor produtividade em conjunto vis-à-vis os de maior produtividade, a análise constata que, além da variação esperada da produtividade ser maior no grupo mais produtivo, o nível médio de produtividade do trabalho neste agrupamento é muito superior ao verificado para os setores de mais baixa produtividade, indicando um aumento da heterogeneidade estrutural da indústria brasileira.

Sintetizando os argumentos relativos ao impacto da mudança estrutural sobre a produtividade, de Negri e Cavalcante (2014) sugerem que a mudança estrutural ocorrida na economia brasileira, nos anos 2000, não foi tão forte e não teve efeitos negativos sobre a produtividade agregada, como se poderia pensar a priori. Além disso, dada a estrutura produtiva atual, não pareceria haver potencial para que mudanças estruturais fossem capazes de gerar ganhos expressivos de produtividade agregada, pelo menos em termos dos grandes macrossetores, apesar de, aparentemente, haver indícios de que mudanças na estrutura interna desses macrossetores podem ter efeitos relevantes sobre a produtividade agregada.Na 
medida em que o componente estrutural não seria capaz de explicar completamente a baixa produtividade do Brasil, explicações complementares seriam necessárias, contemplando um foco tanto em fatores sistêmicos, quanto numa abordagem microeconômica centrada nas decisões empresariais, que poderiam explicar os diferenciais de produtividade dentro de um mesmo setor de atividade.

A baixa produtividade da indústria de transformação no Brasil parece também estar relacionada à dificuldade de inovação do setor, agravada pelos problemas decorrentes dos baixos níveis de qualificação da mão de obra, amplificados numa economia mais próxima do pleno emprego. Além disso, no plano intersetorial, o crescimento do setor serviços e o da agropecuária teriam ocorrido via modernização, de modo a que o crescimento da produtividade nesses setores fosse relativamente maior do que na indústria de transformação (Torres; Kupfer, 2011), o que favoreceria a convergência do nível de produtividade dos macrossetores menos produtivos (serviços e agropecuária) com o macrossetor de maior produtividade, a indústria. A análise de Moreira (2015), por sua vez, discute os efeitos da elevada e crescente descentralização da produção na produtividade, apresentando evidências de que a produtividade entre parceiros de produção é bastante desigual, existindo uma correlação forte e negativa entre heterogeneidade de produtividade e produtividade setorial e agregada. Além disso, essa análise encontra evidências de que os serviços - em especial os mais sofisticados - têm impacto importante na produtividade dos setores que os consomem como bens intermediária.

\section{2 - Metodologia de Análise dos Dados da PIA para o período 1996-2013}

A análise desenvolvida a seguir procura incorporar as variações de preços no tratamento de indicadores e considerar impactos do processo em termos da configuração setorial da indústria, de modo a qualificar argumentos tradicionais elaborados pela literatura recente que aborda o fenômeno da desindustrialização e a buscar evidências de mudança estrutural e de fontes de dinamismo da indústria. A análise desenvolvida aponta para qualificações importantes do diagnóstico geral de mudança estrutural regressiva e perda de relevância e dinamismo da indústria brasileira. Por um lado, apresentam-se evidências de que a direção e a intensidade da mudança estrutural devem ser relativizadas quando se realizam ajustamentos nos indicadores utilizados com base nas variações dos diferentes preços setoriais e quando essa tendência geral é referenciada a diferentes subperíodos de análise. Por outro lado, há também evidências de que os efeitos desse movimento, em termos de indicadores relacionados à evolução de indicadores de produtividade, devem ser investigados em maior detalhe, a partir da incorporação de um recorte intersetorial à análise.

De modo a captar as transformações produtivas corridas na indústria brasileira, dois princípios gerais orientam a análise. Por um lado, procurou-se considerar uma periodização que, apesar de arbitrária, fosse funcional para analisar os miniciclos de retração e crescimento da indústria, optando-se, nessa direção, pela análise de períodos trienais entre 1996-2013. A seleção desse período decorreu da disponibilidade de informações extraídas da PIA-IBGE segundo um recorte setorial homogêneo. Por outro lado, em termos do recorte setorial, procurou-se considerar um recorte homogêneo para todo o período, o que envolve adaptações devido à transição da CNAE 1.0 para a CNAE 2.0 a partir da PIA2007. Procurou-se também adotar um recorte setorial suficientemente abrangente, em função da heterogeneidade da indústria brasileira, que dificulta a utilização de critérios de "classificação" de setores industriais excessivamente rígidos. Especificamente, optou-se por um recorte que distingue 26 setores, que se aproximam da classificação a dois dígitos da CNAE, a partir dos quais é possível apontar as múltiplas direções das transformações produtivas ocorridas na indústria brasileira no período em análise.

Do ponto de vista metodológico, a investigação empírica recorre a informações disponibilizadas pela Pesquisa Industrial Anual (PIA- IBGE), para um período de dezoito anos (1996-2013), baseadas num recorte setorial abrangente que procura captar o processo de mudança estrutural da indústria. A análise das transformações experimentadas pela indústria é desenvolvida a partir de dois princípios gerais. Por um lado, procurou-se considerar uma periodização que, apesar de arbitrária, fosse funcional para analisar os miniciclos de retração e crescimento da indústria, optando-se, nessa direção, pela análise de períodos trienais entre 1996-2013. Por outro lado, em termos do recorte setorial, procurou-se considerar um recorte homogêneo para todo o período, o que envolve adaptações devido à transição da CNAE 1.0 para a CNAE 2.0 a partir da PIA- 2007. Em particular, optou-se por um recorte setorial suficientemente abrangente, em 
função da heterogeneidade da indústria brasileira, que dificulta a utilização de critérios de "classificação" de setores industriais excessivamente rígidos. Especificamente, optou-se por um recorte que distingue 26 setores, agregando indústria extrativa e de transformação, que se aproximam da classificação a dois dígitos da CNAE, a partir dos quais é possível apontar as múltiplas direções das transformações produtivas ocorridas na indústria brasileira no período em análise.

Para avaliar a dinâmica desse processo, optou-se por articular o recorte setorial mencionado à análise de um conjunto de indicadores extraídos da PIA-IBGE. No caso de indicadores expressos em valores monetários optou-se por deflacionar os valores nominais na construção das séries, por meio da utilização de deflatores setoriais específicos calculados com base nos IPA setoriais disponibilizados pela FGV. Para estes indicadores básicos, considerou-se a distribuição setorial e as taxas anuais de crescimento dos mesmos. Para analisar-se a dinâmica de evolução desses indicadores, valores médios referentes à estrutura (distribuição) e ao crescimento (dinamismo) dos mesmos foram calculados para seis subperíodos - 1996-1998, 1999-2001, 2002-2004, 2005-2007, 2008-2010 e 2011-2013 - bem como para a média anual de todo o período 1996-2013. A análise desagregada desses indicadores para diferentes setores, sobreposta a um recorte temporal que distingue diferentes subperíodos, possibilita captar aspectos relevantes da mudança estrutural da indústria ao longo do período considerado.

\section{3 - Evolução Geral da Produtividade e Ajuste Produtivo na Indústria Brasileira}

Um dos principais argumentos da literatura que discute o baixo dinamismo da indústria brasileira no período recente refere-se à estagnação da produtividade, cujos impactos seriam potencialmente reforçados pela elevação comparativa dos salários industriais, impulsionada por uma situação próxima do pleno-emprego, o que teria potencial para gerar um processo de profit-squeeze, originando, dessa forma, um círculo vicioso de baixa rentabilidade, retração de investimentos e baixo ritmo de crescimento do produto. O Gráfico 1 e a Tabela 1 permitem qualificar melhor essa discussão, apresentando informações sobre valores médios trienais e sobre taxas anuais de crescimento referentes ao Pessoal ocupado, ao Valor da Transformação Industrial, aos Salários, retiradas e outras remunerações, à Produtividade (medida pela relação entre VTI e pessoal ocupado) e ao Salário Médio (medido pela relação entre salários e pessoal ocupado) para o período 1996-2013. Os valores monetários, como de praxe no trabalho, foram deflacionados a partir de deflatores setoriais específicos.

Inicialmente cabe uma discussão sobre a evolução da Produtividade e do Salário Médio em função dos indicadores que os definem. O comportamento geral medíocre da produtividade do trabalho - com crescimento médio anual de $0,2 \%$ ao ano ao longo do período investigado, reflete a evolução geral do Valor da Transformação Industrial - com crescimento médio anual de 3,4\% ao ano no período comparativamente à evolução do Pessoal ocupado - com crescimento médio anual de 3,3\% ao ano no período. No entanto, a evolução da Produtividade do trabalho nos diferentes subperíodos reflete tendências muitas vezes distintas para o comportamento do Valor da Transformação Industrial e do Pessoal Ocupado. Os dois subperíodos de maior crescimento da Produtividade evidenciam esse aspecto: no subperíodo 1996-1998, esse crescimento (de 4,6\% ao ano), foi impulsionado pela queda do emprego (2,6\% ao ano) comparativamente ao baixo crescimento do VTI (de 1,8\% ao ano); já no subperíodo de 2008-2010, o crescimento da produtividade (de 1,9\% ao ano) foi impulsionado pelo maior crescimento do VTI (6,4\% ao ano) comparativamente ao crescimento também expressivo do emprego (de 4,2\% ao ano). Já no caso do Salário Médio, o baixo crescimento observado, com queda de $0,8 \%$ para o conjunto do período, reflete o menor crescimento dos Salários - com crescimento médio anual de $2,4 \%$ ao ano no período - comparativamente à evolução do Pessoal ocupado - com crescimento médio anual de 3,3\% ao ano no período. Também nesse caso, a evolução do Salário Médio nos diferentes subperíodos reflete as tendências observadas para o comportamento dos Salários e do Pessoal Ocupado. Nesse sentido, três períodos podem ser destacados. Entre 1996-1998, tanto os Salários como o Pessoal Ocupado apresentaram uma queda no período, com maior queda relativa para os Salários, gerando um aumento do Salário Médio. Entre 1999-2003, observa-se uma queda do Salário Médio resultante da queda nos Salários totais, acompanhada por um aumento do Pessoal Ocupado. Por fim, entre 2004-2013, observa-se um aumento do Salário Médio, refletindo aumentos significativos dos Salários acima do crescimento do 
Pessoal Ocupado. Esse movimento reflete um aquecimento do mercado de trabalho na indústria, em uma situação geral de baixo desemprego, que acabou ocasionado pressões altistas sobre os Salários Médios.

A evolução comparada da Produtividade do Trabalho e dos Salários Médios na indústria permite discutir e qualificar os argumentos da literatura. Em primeiro lugar, mesmo constatando-se o baixo crescimento da Produtividade $(0,2 \%$ ao ano), verifica-se que, ao longo do período, o crescimento do Salário Médio foi negativo ( $-0,8 \%$ ao ano). Nesse sentido, o argumento sobre uma "tendência" de crescimento do Salário Médio acima da Produtividade do trabalho dificilmente se sustenta com base nos dados apresentados. Cabe ressaltar que, efetivamente, verifica-se um maior crescimento comparado dos Salários Médios a partir de 2004, com a relação Produtividade/ Salário Médio evoluindo de 5,25 em 2002-2004 para 4,28 em 2011-2013. No entanto, cabe ressaltar que essa evolução se explica, fundamentalmente pelo baixo crescimento da Produtividade. Assim, o argumento do profit-squeeze vinculado aos custos salariais não se sustenta como tendência geral, apesar das evidências de que ele pode ter alguma relevância para explicar características dos períodos mais recentes.

Gráfico 1 - Crescimento do Pessoal ocupado, Valor da transformação industrial, Salários,

Produtividade e Salário Médio - 1996-2013 (1996 = 100)

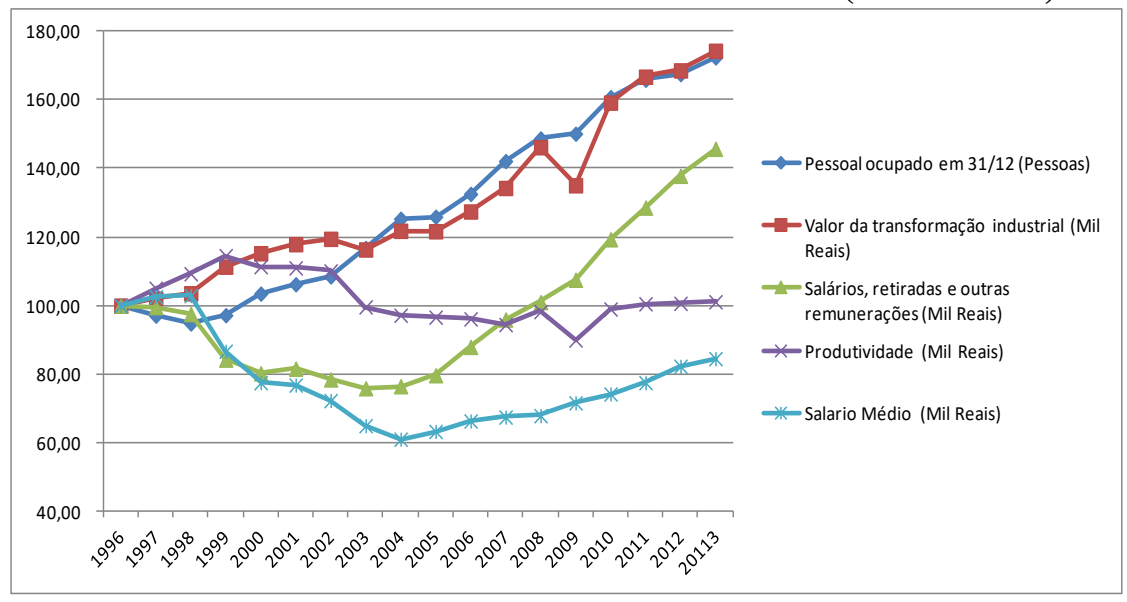

Fonte: elaboração própria a partir de dados da PIA-IBGE

Tabela 1 - Valores médios e Crescimento do Pessoal ocupado, Valor da transformação industrial, Salários, Produtividade e Salário Médio - 1996-2013 e Subperíodos trienais

\begin{tabular}{|c|c|c|c|c|c|c|}
\hline & & $\begin{array}{c}\text { Pessoal ocupado } \\
\text { em 31/12 (Pessoas) }\end{array}$ & $\begin{array}{l}\text { Valor da transformação } \\
\text { industrial (Mil Reais) }\end{array}$ & $\begin{array}{l}\text { Salários, retiradas e outras } \\
\text { remunerações (Mil Reais) }\end{array}$ & $\begin{array}{l}\text { Produtividade } \\
\text { (Mil Reais) }\end{array}$ & $\begin{array}{c}\text { Salário } \\
\text { Médio (Mil } \\
\text { Reais) }\end{array}$ \\
\hline \multirow{6}{*}{$\begin{array}{l}\text { Valores médios } \\
\text { anuais no Período }\end{array}$} & 1996-1998 & 4.768 .516 & 615.462 .886 & 175.789 .535 & 129 & 37 \\
\hline & $1999-2001$ & 5.014 .813 & 694.004 .248 & 145.599 .844 & 138 & 29 \\
\hline & 2002-2004 & 5.729 .236 & 720.388 .669 & 136.581 .810 & 126 & 24 \\
\hline & 2005-2007 & 6.546 .597 & 772.322 .817 & 155.948 .046 & 118 & 24 \\
\hline & $2008-2010$ & 7.511 .638 & 887.274 .277 & 194.012 .916 & 118 & 26 \\
\hline & 2011-2013 & 8.264 .582 & 1.026 .635 .828 & 243.885 .146 & 124 & 29 \\
\hline Média anual & $1996-2013$ & 6.305 .897 & 786.014 .788 & 175.302 .883 & 126 & 28 \\
\hline \multirow{6}{*}{$\begin{array}{l}\text { Crescimento médio } \\
\text { anual no período }\end{array}$} & 1996-1998 & $-2,6 \%$ & $1,8 \%$ & $-1,2 \%$ & $4,6 \%$ & $1,5 \%$ \\
\hline & $1999-2001$ & $3,9 \%$ & $4,4 \%$ & $-5,6 \%$ & $0,6 \%$ & $-9,1 \%$ \\
\hline & 2002-2004 & $5,7 \%$ & $1,1 \%$ & $-2,1 \%$ & $-4,3 \%$ & $-7,4 \%$ \\
\hline & 2005-2007 & $4,3 \%$ & $3,3 \%$ & $7,9 \%$ & $-0,9 \%$ & $3,4 \%$ \\
\hline & $2008-2010$ & $4,2 \%$ & $6,4 \%$ & $7,6 \%$ & $1,9 \%$ & $3,2 \%$ \\
\hline & 2011-2013 & $2,4 \%$ & $3,1 \%$ & $6,9 \%$ & $0,7 \%$ & $4,4 \%$ \\
\hline Var anual & $1996-2013$ & $3,3 \%$ & $3,4 \%$ & $2,4 \%$ & $0,2 \%$ & $-0,8 \%$ \\
\hline
\end{tabular}

Por outro lado, um dos argumentos da literatura discutida de tradição estruturalista refere-se à relevância de um foco na intensidade do processo de investimento na indústria para explicar a sua evolução, o seu dinamismo e as mudanças na sua estrutura. No caso das informações extraídas da PIA, informações sobre Aquisições, melhorias e baixas de ativos tangíveis realizadas no ano podem ser utilizadas como proxis dos investimentos no período 1996-2013. Como no caso de outros indicadores monetários, essas informações foram deflacionadas a partir de deflatores setoriais específicos. Segundo informações apresentadas no Gráfico 2 e na Tabela 2, esses investimentos atingiram, ao longo do 
período considerado, um valor médio anual de $\mathrm{R} \$ 136,6$ bilhões, o que, confrontado com um valor médio do VTI da ordem de R\$ 786 bilhões, resultaria numa Taxa de Investimento (medida pela relação entre Investimento e VTI) da ordem de 17,2\% para a média do período. Ao longo do período, verifica-se uma taxa média de crescimento anual dos Investimentos de 4,5\% ao ano, o que confrontado com um crescimento médio anual do VTI de $3,4 \%$ ao ano, resultava num crescimento médio da Taxa de Investimento de $1,2 \%$ ao ano.

Algumas qualificações importantes em relação a esse movimento geral podem ser identificadas a partir da análise de diferentes subperíodos. Com relação aos Investimentos, após um crescimento médio anual de 3,0\% entre 1996-1998, verifica-se uma evolução medíocre, com taxas médias de crescimento negativas até 2004. Após 2004, verifica-se uma elevação significativa dos Investimentos entre 2004-2008, com impactos na elevação da Taxa de Investimento. Como reflexo, entre 2005-2007 o Investimento cresceu a uma taxa média de 17,2\% ao ano, gerando um crescimento da Taxa de Investimento de 13,3\% ao ano. Entre 2008-2010, verifica-se uma estabilização do nível de Investimento, o que, acompanhado por uma elevação simultânea do VTI, resultou numa tendência à elevação da Taxa de Investimento. Já entre 2010-2012, verifica-se uma reativação do processo de Investimento, que cresceu a uma taxa média de $8,1 \%$ ao ano entre 2011-2013, gerando um aumento de 5,0\% ao ano na Taxa de Investimento. No entanto, no último ano do período (2013), identifica-se uma estabilização dos Investimentos, acompanhado por um decréscimo da Taxa de Investimento.

Em conjunto, as informações apresentadas sugerem que uma eventual hipótese de estagnação da indústria em função da retração de investimento - que poderia justificar algum tipo de argumento a favor do processo de desindustrialização - não encontra fundamento. Pelo contrário, há indícios de que o Investimento na indústria brasileira apresenta uma tendência de crescimento entre 2004-2012, com correspondente elevação da Taxa de Investimento, medida pela relação entre Investimento e VTI. A questão a ser avaliada, que mereceria uma discussão mais cuidadosa, refere-se à "qualidade" desses investimentos, a qual poderia ser correlacionada a três aspectos principais. O primeiro deles, em relação ao qual as informações disponibilizadas pela PIA tem pouco a dizer, refere-se à natureza particular das Aquisições, melhorias e baixas de ativos tangíveis realizadas, no sentido da incorporação de máquinas e equipamentos mais produtivas ou que viabilizem a intensificação de processo inovativos. O segundo aspecto refere-se à configuração intersetorial desses investimentos, no sentido de privilegiar atividades produtivas difusoras de progresso técnico, com potencial de geração de efeitos de encadeamento e transbordamento (spill-over) para o conjunto da indústria. Esse aspecto será discutido parcialmente à frente, quando for detalhada a configuração intersetorial dos investimentos realizados. Um terceiro aspecto refere-se à maneira como o processo de investimento é afetado pela evolução de outros indicadores relacionados ao desempenho econômico e produtivo do setor industrial.

\section{Gráfico 2 - Crescimento do Valor da Transformação industrial, Ativo Imobilizado (Investimentos) e da Taxa de Investimento - 1996-2013 (1996 = 100)}

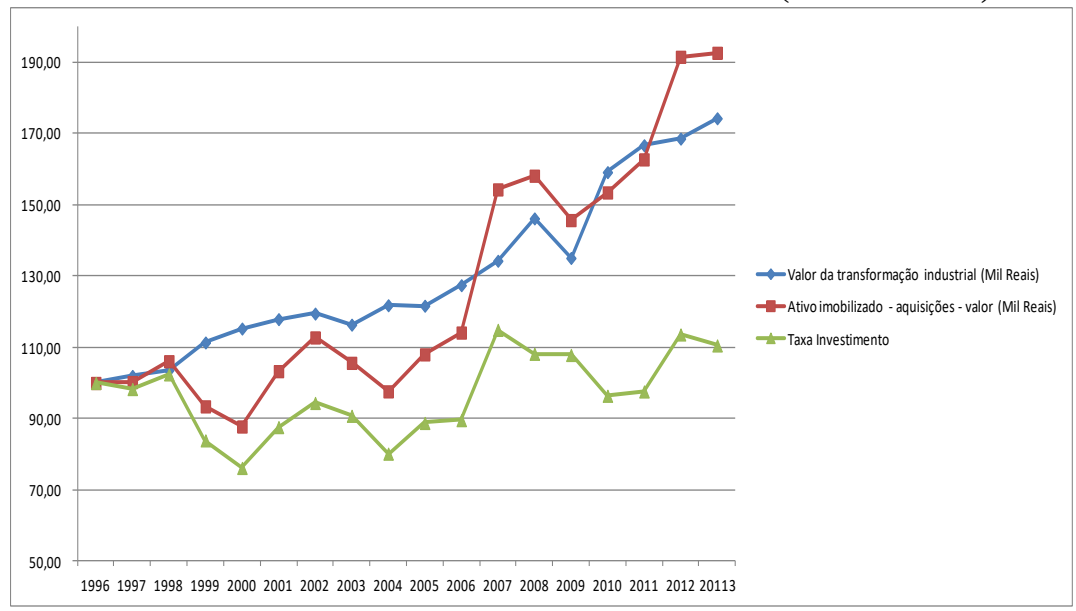

Fonte: elaboração própria a partir de dados da PIA-IBGE 
Tabela 2 - Valores médios e Crescimento do Valor da Transformação industrial, Ativo Imobilizado (Investimentos) e da Taxa de Investimento - 1996-2013 e Subperíodos trienais

\begin{tabular}{|c|c|c|c|c|}
\hline & & $\begin{array}{c}\text { Valor da } \\
\text { transformação } \\
\text { industrial (Mil } \\
\text { Reais) }\end{array}$ & $\begin{array}{l}\text { Ativo imobilizado - } \\
\text { aquisições - valor } \\
\text { (Mil Reais) }\end{array}$ & Taxa Investimento \\
\hline $\begin{array}{l}\text { Valores médios } \\
\text { anuais no Período }\end{array}$ & $\begin{array}{l}1996-1998 \\
1999-2001 \\
2002-2004 \\
2005-2007 \\
2008-2010 \\
2011-2013 \\
\end{array}$ & $\begin{array}{c}615.462 .886 \\
694.004 .248 \\
720.388 .669 \\
772.322 .817 \\
887.274 .277 \\
1.026 .635 .828 \\
\end{array}$ & $\begin{array}{l}109.765 .245 \\
101.939 .737 \\
113.248 .735 \\
134.913 .888 \\
163.905 .960 \\
196.033 .310\end{array}$ & $\begin{array}{l}17,8 \% \\
14,7 \% \\
15,7 \% \\
17,4 \% \\
18,5 \% \\
19,1 \% \\
\end{array}$ \\
\hline Média Anual & $1996-2013$ & 786.014 .788 & 136.634 .479 & $17,2 \%$ \\
\hline $\begin{array}{l}\text { Crescimento } \\
\text { médio anual no } \\
\text { período }\end{array}$ & $\begin{array}{l}1996-1998 \\
1999-2001 \\
2002-2004 \\
2005-2007 \\
2008-2010 \\
2011-2013 \\
\end{array}$ & $\begin{array}{l}1,8 \% \\
4,4 \% \\
1,1 \% \\
3,3 \% \\
6,4 \% \\
3,1 \% \\
\end{array}$ & $\begin{array}{c}3,0 \% \\
-0,1 \% \\
-1,6 \% \\
17,2 \% \\
0,0 \% \\
8,1 \% \\
\end{array}$ & $\begin{array}{c}1,2 \% \\
-4,1 \% \\
-2,6 \% \\
13,3 \% \\
-5,6 \% \\
5,0 \% \\
\end{array}$ \\
\hline Var anual & 1996-2013 & $3,4 \%$ & $4,5 \%$ & $1,2 \%$ \\
\hline
\end{tabular}

Fonte: elaboração própria a partir de dados da PIA-IBGE

Avaliando a articulação entre o investimento outros indicadores, é possível supor que o processo de investimento depende da rentabilidade gerada nas atividades industriais. Nesse sentido, o Gráfico 3 e a Tabela 3 apresentam uma evolução comparada do Investimento, do VTI e dos Lucros Totais entre 1996 e 2013. De início, cabe observar os valore médios anuais do Investimento e dos Lucros Totais no período: os valores médios do Investimento atingiam R \$ 136,6 bilhões, contra uma média de R $\$ 152$ bilhões dos Lucros Totais. Considerando a evolução comparada dos dois indicadores, verifica-se que, entre 19962001, os valores médios anuais dos Investimentos localizam-se acima dos Lucros Totais, tendência que é revertida para o período 2002-2010, com maiores valores dos Lucros Totais, e que ressurge no período 2011-2013. Em termos das taxas de crescimento, cabe destacar o maior valor dos Investimentos comparativamente aos Lucros Totais nos períodos 2005-2007 e 2011-2013. Já no período 2008-2010 verifica-se uma retração dos Investimentos em função do cenário mais conturbado, reflexo da crise internacional. Por outro lado, a análise do Gráfico 10 permite identificar dois grandes períodos com tendências distintas. O período 2003-2007 é marcado por uma elevação simultânea dos Investimentos e dos Lucros Totais, revelando uma articulação virtuosa entre os dois indicadores. Já o período 2010-2013 é marcado por um crescimento dos Investimentos acompanhado por uma retração dos Lucros Totais, evidenciando um descolamento dos dois indicadores, o que pode ser explicado, em boa medida, pela evolução intersetorial desses indicadores, a ser discutida mais à frente nesse trabalho. De qualquer modo, essas evidências reforçam a relevância do caráter relativamente "autônomo" das decisões de investimentos, que tendem a ser afetadas por expectativas que se manifestam de forma diferente nos diversos setores.

Gráfico 3- Crescimento do Valor da Transformação industrial, Ativo Imobilizado (Investimentos) e dos Lucros Totais - 1996-2013 (1996 = 100)

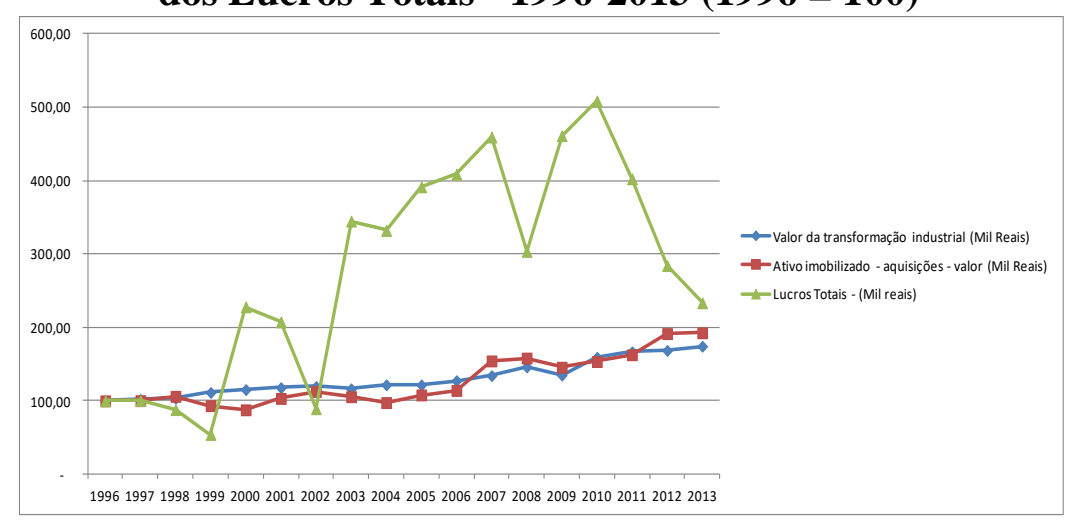

Fonte: elaboração própria a partir de dados da PIA-IBGE 
Tabela 3 - Valores médios e Crescimento do Valor da Transformação industrial, Ativo Imobilizado (Investimentos) e dos Lucros Totais- 1996-2013 e Subperíodos trienais

\begin{tabular}{llrrr}
\hline & & $\begin{array}{l}\text { Valor da } \\
\text { transformação } \\
\text { industrial (Mil Reais) }\end{array}$ & $\begin{array}{l}\text { Ativo imobilizado - } \\
\text { aquisições - valor (Mil } \\
\text { Reais) }\end{array}$ & \multicolumn{2}{l}{$\begin{array}{l}\text { Lucros Totais - (Mil } \\
\text { reais) }\end{array}$} \\
\hline & $\mathbf{1 9 9 6 - 1 9 9 8}$ & 615.462 .886 & 109.765 .245 & 52.678 .292 \\
Valores médios & $\mathbf{1 9 9 9 - 2 0 0 1}$ & 694.004 .248 & 101.939 .737 & 89.400 .598 \\
anuais no & $\mathbf{2 0 0 2 - 2 0 0 4}$ & 720.388 .669 & 113.248 .735 & 139.853 .829 \\
Período & $\mathbf{2 0 0 5 - 2 0 0 7}$ & 772.322 .817 & 134.913 .888 & 229.878 .729 \\
& $\mathbf{2 0 0 8 - 2 0 1 0}$ & 887.274 .277 & 163.905 .960 & 232.374 .099 \\
& $\mathbf{2 0 1 1 - 2 0 1 3}$ & 1.026 .635 .828 & 196.033 .310 & 167.947 .832 \\
\hline Média anual & $\mathbf{1 9 9 6 - 2 0 1 3}$ & 786.014 .788 & 136.634 .479 & 152.022 .230 \\
\hline & $\mathbf{1 9 9 6 - 1 9 9 8}$ & $1,8 \%$ & $3,0 \%$ & $-5,9 \%$ \\
Crescimento & $\mathbf{1 9 9 9 - 2 0 0 1}$ & $4,4 \%$ & $-0,1 \%$ & $90,9 \%$ \\
médio anual no & $\mathbf{2 0 0 2 - 2 0 0 4}$ & $1,1 \%$ & $-1,6 \%$ & $75,2 \%$ \\
período & $\mathbf{2 0 0 5 - 2 0 0 7}$ & $3,3 \%$ & $17,2 \%$ & $11,5 \%$ \\
& $\mathbf{2 0 0 8 - 2 0 1 0}$ & $6,4 \%$ & $0,0 \%$ & $9,4 \%$ \\
& $\mathbf{2 0 1 1 - 2 0 1 3}$ & $3,1 \%$ & $8,1 \%$ & $-22,7 \%$ \\
\hline Var anual & $\mathbf{1 9 9 6 - 2 0 1 3}$ & $3,4 \%$ & $4,5 \%$ & $28,3 \%$ \\
\hline
\end{tabular}

Fonte: elaboração própria a partir de dados da PIA-IBGE

Uma importante articulação a ser mencionada diz respeito à evolução comparada da evolução dos Investimentos, da Produtividade, do Salário Médio e dos Serviços industriais prestados por terceiros, ilustrada pelo Gráfico 4 e pela Tabela 4. Por um lado, verifica-se que a aceleração dos Investimentos no período pós-2004 ocorreu à revelia de um crescimento da Produtividade, que permaneceu relativamente estagnada durante aquele período. Provavelmente, essa tendência indica que as atividades que sustentaram esses investimentos não foram capazes de promover um aumento generalizado da produtividade na indústria, podendo-se sugerir que uma parcela desse impacto "vazou" para fora da indústria, seja na forma da aquisição de serviços e/ou de importações. Essa tendência pode ser captada pela forte "aderência" observada entre o crescimento dos Investimentos e o crescimento dos Serviços industriais prestados por terceiros. Por outro lado, a evolução comparada da evolução dos Investimentos e dos Salários Médios revela um crescimento simultâneo dos dois indicadores no período pós-2005, o que também sugere que o crescimento dos Salários Médios não foi capaz de criar constrangimentos à realização de Investimentos por meio de algum tipo de profit-squeeze.

\section{Gráfico 4 - Crescimento do Ativo Imobilizado (Investimentos), Produtividade, Salário Médio e} Serviços industriais prestados por terceiros - 1996-2013 $(1996=100)$

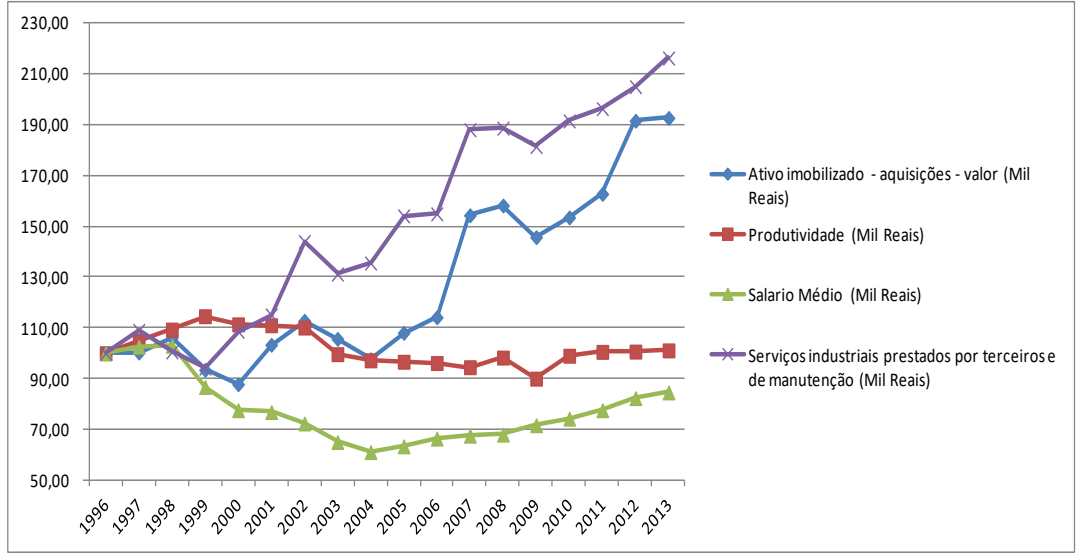

Fonte: elaboração própria a partir de dados da PIA-IBGE 
Tabela 4 - Valores médios e Crescimento do Ativo Imobilizado (Investimentos), Produtividade, Salário Médio e Serviços industriais prestados por terceiros - 1996-2013 e Subperíodos trienais

\begin{tabular}{|c|c|c|c|c|c|}
\hline & & $\begin{array}{l}\text { Ativo imobilizado - } \\
\text { aquisições - valor } \\
\text { (Mil Reais) }\end{array}$ & $\begin{array}{c}\text { Produtividade (Mil } \\
\text { Reais) }\end{array}$ & $\begin{array}{c}\text { Salário Médio (Mil } \\
\text { Reais) }\end{array}$ & $\begin{array}{c}\text { Serviços industriais } \\
\text { prestados por } \\
\text { terceiros e de } \\
\text { manutenção (Mil } \\
\text { Reais) }\end{array}$ \\
\hline \multirow{6}{*}{ Valores médios anuais no Período } & 1996-1998 & 109.765 .245 & 129 & 37 & 41.294 .554 \\
\hline & $1999-2001$ & 101.939 .737 & 138 & 29 & 42.400 .923 \\
\hline & 2002-2004 & 113.248 .735 & 126 & 24 & 54.802 .512 \\
\hline & 2005-2007 & 134.913 .888 & 118 & 24 & 66.315 .412 \\
\hline & 2008-2010 & 163.905 .960 & 118 & 26 & 74.933 .914 \\
\hline & 2011-2013 & 196.033 .310 & 124 & 29 & 82.408 .475 \\
\hline Média Anual & $1996-2013$ & 136.634 .479 & 126 & 28 & 60.359 .298 \\
\hline \multirow{6}{*}{ Crescimento médio anual no período } & 1996-1998 & $3,0 \%$ & $4,6 \%$ & $1,5 \%$ & $0,6 \%$ \\
\hline & 1999-2001 & $-0,1 \%$ & $0,6 \%$ & $-9,1 \%$ & $5,0 \%$ \\
\hline & 2002-2004 & $-1,6 \%$ & $-4,3 \%$ & $-7,4 \%$ & $6,5 \%$ \\
\hline & 2005-2007 & $17,2 \%$ & $-0,9 \%$ & $3,4 \%$ & $11,9 \%$ \\
\hline & 2008-2010 & $0,0 \%$ & $1,9 \%$ & $3,2 \%$ & $0,7 \%$ \\
\hline & 2011-2013 & $8,1 \%$ & $0,7 \%$ & $4,4 \%$ & $4,1 \%$ \\
\hline Var anual & 1996-2013 & $4,5 \%$ & $0,2 \%$ & $-0,8 \%$ & $5,1 \%$ \\
\hline
\end{tabular}

Fonte: elaboração própria a partir de dados da PIA-IBGE

Um dos argumentos da literatura, especialmente em algumas análises de tradição estruturalista, é que a trajetória recente da indústria brasileira revelaria a realização de importantes ajustes produtivos (Bielschowsky, 2012; Kupfer,2012; Morcero, 2012; Sarti e Hiratuka, 2011). Por um lado, algumas análises ressaltam que esses ajustes revelariam uma perda de adensamento da estrutura produtiva, com menor incorporação de insumos e componentes produzidos internamente, o que teria impactos na redução do indicador dado pela relação entre o Valor da Transformação Industrial e o Valor Bruto da Produção, visto como uma medida da agregação de valor pela indústria. Contrastando com essa tendência aparentemente negativa, outras análises ressaltam como tendência importante a crescente incorporação de serviços às atividades industriais. Os indicadores extraídos de dados da PIA para o conjunto da indústria ajudam a qualificar melhor essas tendências.

O Gráfico 5 e a Tabela 5 apresentam uma evolução comparada do Valor da transformação industrial, do Consumo de matérias primas, materiais auxiliares e componentes, do Consumo de peças, acessórios e pequenas ferramentas e de um Índice de Agregação de Valor (dado pela relação VTI/VBPF). Em termos dos valores médios anuais, verifica-se que o Consumo de peças, acessórios e pequenas ferramentas permaneceu em torno de $\mathrm{R} \$ 25-30$ bilhões ano, enquanto o VTI e o Consumo geral de matérias primas, materiais auxiliares e componentes apresentam uma evolução de algo em torno de $\mathrm{R} \$$ 600 bilhões para mais de RS 1.000 bilhões ao longo do período. Como reflexo, observa-se, para o conjunto do período, um maior crescimento médio anual das Matérias primas, materiais auxiliares e componentes - de 4,1\% ao ano - e do Valor da transformação industrial - de 3,4\% ao ano comparativamente ao menor crescimento do Consumo de peças, acessórios e pequenas ferramentas - de 1,9\% ao ano. Em função dessas tendências, observa-se uma leve queda do índice de Agregação de Valor ao longo do período. Em termos dos diversos subperíodos, cabe destacar o expressivo crescimento do Consumo de matérias primas, materiais auxiliares e componentes no período mais recente, o que provavelmente pode ser explicado por mudanças na composição setorial do produto industrial, a ser melhor discutida à frente. Além disso, a aquisição de peças, acessórios e pequenas ferramentas, apesar do menor crescimento, apresenta uma aceleração importante entre 2012 e 2013. Essas tendências, não obstante as evidências de pequena queda no índice de agregação de valor - que, conforme já mencionado, é uma medida sujeita a críticas metodológicas - aponta para a necessidade de se relativizar o argumento da perda de densidade da estrutura produtiva. Aparentemente, essa perda de densidade é melhor caracterizada como um fenômeno localizado em determinados setores (ou cadeias produtivas), conforme será discutido à frente nesse trabalho. 
Gráfico 5 - Crescimento do Valor da transformação industrial, do Consumo de matérias primas, materiais auxiliares e componentes, do Consumo de peças, acessórios e pequenas ferramentas e de Índice de Agregação de Valor (VTI/VBPF) - 1996-2013 (1996 = 100)

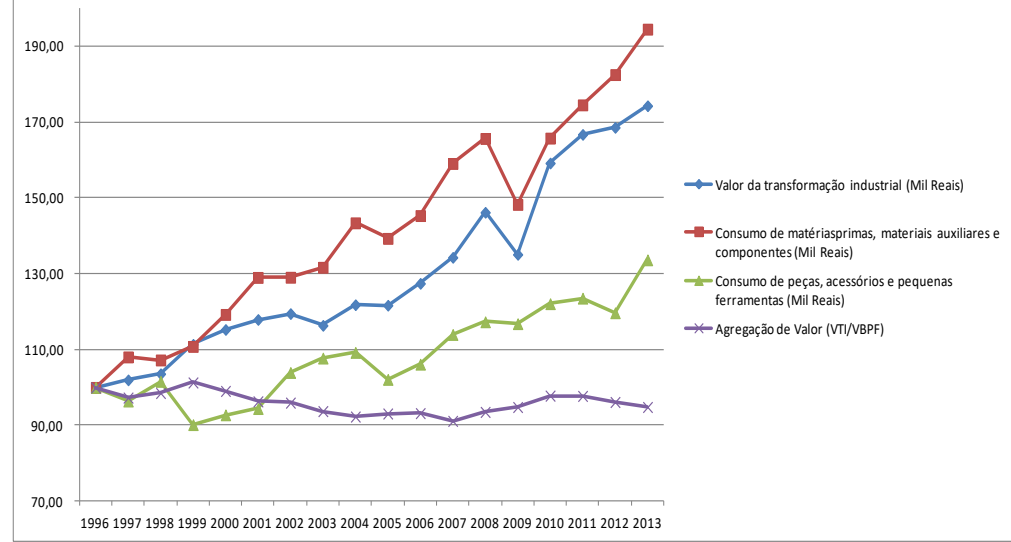

Fonte: elaboração própria a partir de dados da PIA-IBGE

Tabela 5 - Valores médios e Crescimento do Valor da transformação industrial, do Consumo de matérias primas, materiais auxiliares e componentes, do Consumo de peças, acessórios e pequenas ferramentas e de Índice de Agregação de Valor (VTI/VBPF). - 1996-2013 e Subperíodos trienais

\begin{tabular}{|c|c|c|c|c|c|}
\hline & & $\begin{array}{c}\text { Valor da } \\
\text { transformação } \\
\text { industrial (Mil } \\
\text { Reais) }\end{array}$ & $\begin{array}{c}\text { Consumo de } \\
\text { matérias primas, } \\
\text { materiais auxiliares } \\
\text { e componentes (Mil } \\
\text { Reais) }\end{array}$ & $\begin{array}{l}\text { Consumo de peças, } \\
\text { acessórios e } \\
\text { pequenas } \\
\text { ferramentas (Mil } \\
\text { Reais) }\end{array}$ & $\begin{array}{c}\text { Agregaçãa de Valor } \\
\text { (VTI/VBPF) }\end{array}$ \\
\hline \multirow{6}{*}{$\begin{array}{l}\text { Valores médios } \\
\text { anuais no } \\
\text { Período }\end{array}$} & 1996-1998 & 615.462 .886 & 604.411 .884 & 24.202 .990 & $46,5 \%$ \\
\hline & 1999-2001 & 694.004 .248 & 688.424 .015 & 22.526 .490 & $46,6 \%$ \\
\hline & 2002-2004 & 720.388 .669 & 774.877 .193 & 26.065 .053 & $44,3 \%$ \\
\hline & 2005-2007 & 772.322 .817 & 850.763 .793 & 26.171 .177 & $43,6 \%$ \\
\hline & 2008-2010 & 887.274 .277 & 919.796 .936 & 28.933 .273 & $45,0 \%$ \\
\hline & 2011-2013 & 1.026 .635 .828 & 1.057.629.924 & 30.613 .163 & $45,4 \%$ \\
\hline Média Anual & $1996-2013$ & 786.014 .788 & 815.983 .958 & 26.418 .691 & $45,3 \%$ \\
\hline \multirow{6}{*}{$\begin{array}{l}\text { Crescimento } \\
\text { médio anual no } \\
\text { período }\end{array}$} & 1996-1998 & $1,8 \%$ & $3,6 \%$ & $0,9 \%$ & $-0,7 \%$ \\
\hline & 1999-2001 & $4,4 \%$ & $6,4 \%$ & $-2,2 \%$ & $-0,7 \%$ \\
\hline & 2002-2004 & $1,1 \%$ & $3,7 \%$ & $5,0 \%$ & $-1,4 \%$ \\
\hline & 2005-2007 & $3,3 \%$ & $3,6 \%$ & $1,6 \%$ & $-0,4 \%$ \\
\hline & $2008-2010$ & $6,4 \%$ & $1,8 \%$ & $2,3 \%$ & $2,4 \%$ \\
\hline & 2011-2013 & $3,1 \%$ & $5,5 \%$ & $3,2 \%$ & $-1,0 \%$ \\
\hline Var anual & $1996-2013$ & $3,4 \%$ & $4,1 \%$ & $1,9 \%$ & $-0,3 \%$ \\
\hline
\end{tabular}

Fonte: elaboração própria a partir de dados da PIA-IBGE

$\mathrm{O}$ outro argumento da literatura, referente à crescente incorporação de serviços às atividades industriais (Arbache, 2012, 2014), também pode ser ilustrado e respaldado a partir de informações da PIA para o período 1996-2013. Neste sentido, o Gráfico 6 e a Tabela 6 apresentam informações sobre a Produtividade, o índice de Agregação de Valor (dado pela relação VTI/VBPF) e um índice de Intensidade serviços na indústria, dado pela relação entre a soma do Custo das mercadorias adquiridas para revenda e dos Serviços industriais prestados por terceiros e de manutenção e o Valor Adicionado gerado na indústria. A partir das informações apresentadas, verifica-se que o crescimento médio anual do índice de Intensidade no uso de serviços (de 2,2\% ao ano entre 1996-2013) foi expressivamente superior ao crescimento da produtividade (de $0,2 \%$ ao ano) e à evolução do índice de agregação de valor (com queda de $0,3 \%$ ao ano no período). Além disso, no caso do índice de Intensidade do uso de serviços na indústria, observa-se um crescimento particularmente expressivo no período mais recente, com taxa de crescimento de 9,5\% ao ano entre 20011-2013. No entanto, para se identificar se há indícios de que essa maior Intensidade do uso de serviços efetivamente reflete um ajuste "positivo" comprometido com o aumento da agregação de valor e da competitividade da indústria, é importante avançar na direção de uma análise intersetorial mais detalhada, a ser explorada na próxima seção do trabalho. 


\section{Gráfico 6 - Crescimento da Produtividade, do índice de Agregação de Valor (VTI/VBPF) e de}

índice de Intensidade serviços na indústria- 1996-2013 (1996 = 100)

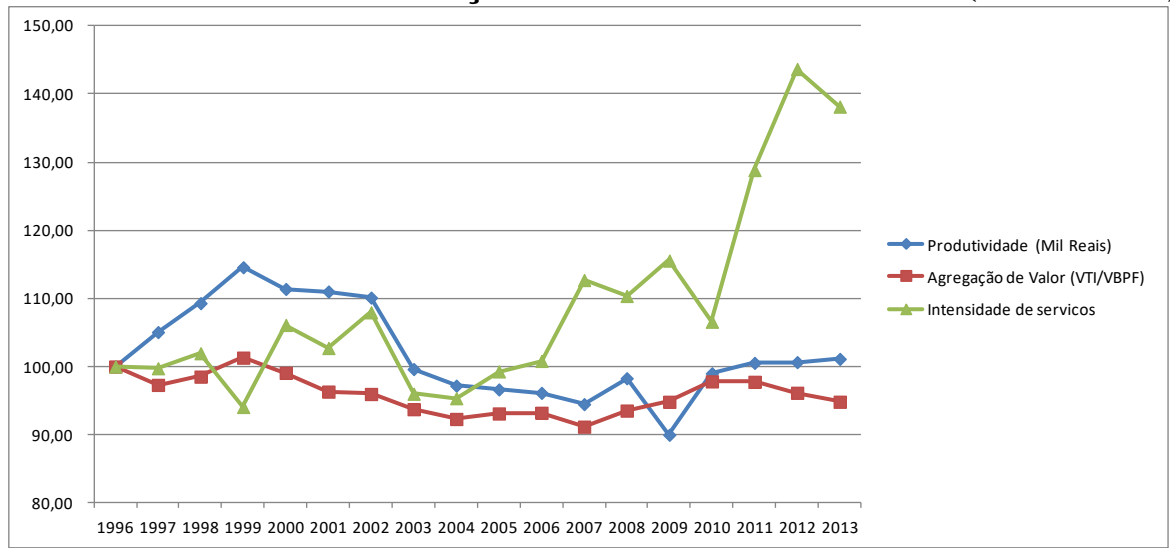

Fonte: elaboração própria a partir de dados da PIA-IBGE

Tabela 6 - Valores médios e Crescimento da Produtividade, do índice de Agregação de Valor (VTI/VBPF) e de índice de Intensidade serviços na indústria - 1996-2013 e Subperíodos trienais

\begin{tabular}{|c|c|c|c|c|}
\hline & & $\begin{array}{c}\text { Produtividade } \\
\text { (Mil Reais) }\end{array}$ & $\begin{array}{c}\text { Agregação de } \\
\text { Valor } \\
\text { (VTI/VBPF) }\end{array}$ & $\begin{array}{c}\text { Intensidade } \\
\text { serviços }\end{array}$ \\
\hline $\begin{array}{l}\text { Valores médios } \\
\text { anuais no Período }\end{array}$ & $\begin{array}{l}1996-1998 \\
1999-2001 \\
2002-2004 \\
2005-2007 \\
2008-2010 \\
2011-2013\end{array}$ & $\begin{array}{l}129 \\
138 \\
126 \\
118 \\
118 \\
124\end{array}$ & $\begin{array}{l}46,5 \% \\
46,6 \% \\
44,3 \% \\
43,6 \% \\
45,0 \% \\
45,4 \% \\
\end{array}$ & $\begin{array}{l}29,3 \% \\
29,5 \% \\
29,1 \% \\
30,5 \% \\
32,2 \% \\
39,9 \% \\
\end{array}$ \\
\hline Média anual & 1996-2013 & 126 & $45,3 \%$ & $32,5 \%$ \\
\hline $\begin{array}{l}\text { Crescimento médio } \\
\text { anual no período }\end{array}$ & $\begin{array}{l}1996-1998 \\
1999-2001 \\
2002-2004 \\
2005-2007 \\
2008-2010 \\
2011-2013\end{array}$ & $\begin{array}{c}4,6 \% \\
0,6 \% \\
-4,3 \% \\
-0,9 \% \\
1,9 \% \\
0,7 \%\end{array}$ & $\begin{array}{c}-0,7 \% \\
-0,7 \% \\
-1,4 \% \\
-0,4 \% \\
2,4 \% \\
-1,0 \% \\
\end{array}$ & $\begin{array}{c}1,0 \% \\
0,6 \% \\
-2,2 \% \\
5,8 \% \\
-1,7 \% \\
9,5 \% \\
\end{array}$ \\
\hline Var anual & 1996-2013 & $0,2 \%$ & $-0,3 \%$ & $2,2 \%$ \\
\hline
\end{tabular}

Fonte: elaboração própria a partir de dados da PIA-IBGE

\section{3- Evolução Inter-setorial da Produtividade e Heterogeneidade da Indústria}

A partir de informações extraídas da PIA, percebe-se que alguns indicadores de desempenho das firmas industriais apresentam significativas diferenças intersetoriais. Dentre esses indicadores, a literatura costuma atribuir particular relevância à Produtividade. A Tabela 7 apresenta a distribuição setorial e a variação da Produtividade, medida em termos da relação VTI por empregado, para a média anual do período e para subperíodos selecionados. Para a média do período, maiores valores em termos de Produtividade são observados nos setores de Petróleo; Extrativa - Ferrosos e Não ferrosos; Siderurgia e metalurgia básica; Farmacêutica; Bebidas. Em contraste, menores valores médios da Produtividade são observados nos setores de Couro e calçados; Têxtil e vestuário; Madeira e móveis; Equipamentos e materiais médicos. Cabe destacar também os setores que apresentaram um aumento da Produtividade, comparativamente àqueles com decréscimo. Comparando-se as médias dos triênios iniciais e finais, verifica-se que 11 setores tiveram um aumento da Produtividade e 15 outros um decréscimo da Produtividade. Neste sentido, oito setores podem ser destacados por apresentarem uma taxa de crescimento médio anual elevado da Produtividade, comparativamente ao baixo crescimento anual geral da Produtividade para o conjunto da indústria no período (de apenas 0,2\% ao ano): Aeroespacial; Equipamentos e materiais médicos; Comunicação, áudio, vídeo e ótica; Eletrônica e informática; Outros equipamentos de transporte; Naval; Automotiva. Em particular, observa-se que, dos 10 setores com maior valor da Produtividade, apenas quatro apresentaram um crescimento positivo para a média do período: Aeroespacial; Extrativa - Ferrosos e Não ferrosos; Celulose e papel; Petróleo. No entanto, existem particularidades importantes nessas trajetórias, pois os setores de Petróleo e Extrativa - Ferrosos e Não 
ferrosos experimentaram um maior crescimento entre 1999-205, seguido de uma posterior desaceleração do mesmo, enquanto o setor Aeroespacial apresenta uma retomada desse crescimento após 2009. Por outro lado, entre os principais setores em termos de VTI, aqueles que apresentam um maior crescimento anual da Produtividade são os de Automotiva; Extrativa - Ferrosos e Não ferrosos; Petróleo. No período mais recente, cabe também destacar a recuperação da Produtividade do setor Automotivo e de Máquinas e Equipamentos.

Tabela 7 - Distribuição setorial e taxas de crescimento setoriais - Produtividade (VTI por empregado) - Média geral anual do período e médias para subperíodos selecionados

\begin{tabular}{|c|c|c|c|c|c|c|c|c|}
\hline & \multicolumn{4}{|c|}{ Distribuição Setorial } & \multicolumn{4}{|c|}{ Variações Médias Anuais } \\
\hline & $\begin{array}{l}1996- \\
1998\end{array}$ & $\begin{array}{l}2011- \\
2013\end{array}$ & Média & Var & $\begin{array}{l}1996- \\
2001\end{array}$ & $\begin{array}{l}2002- \\
2007\end{array}$ & $\begin{array}{l}\text { 2008- } \\
2013\end{array}$ & $\begin{array}{l}\text { Média } \\
\text { 96-13 }\end{array}$ \\
\hline Petróleo & 1.554 & 1.529 & 2.012 & $-1,3 \%$ & $14,9 \%$ & $-6,3 \%$ & $-3,1 \%$ & $1,0 \%$ \\
\hline $\begin{array}{l}\text { Extrativa - Ferrosos e Não ferrosos } \\
\text { Celulose e papel }\end{array}$ & $\begin{array}{r}1.136 \\
148\end{array}$ & $\begin{array}{l}823 \\
157\end{array}$ & $\begin{array}{r}1.175 \\
153\end{array}$ & $\begin{array}{r}-26,6 \% \\
6,3 \%\end{array}$ & $\begin{array}{r}15,2 \% \\
3,4 \%\end{array}$ & $\begin{array}{l}-9,2 \% \\
-1,0 \%\end{array}$ & $\begin{array}{l}2,3 \% \\
1,5 \%\end{array}$ & $\begin{array}{l}2,0 \% \\
1,2 \%\end{array}$ \\
\hline $\begin{array}{l}\text { Extrativa não metálica e mat. Construção } \\
\text { Madeira e móveis }\end{array}$ & $\begin{array}{l}90 \\
36\end{array}$ & $\begin{array}{l}79 \\
50 \\
\end{array}$ & $\begin{array}{l}79 \\
42 \\
\end{array}$ & $\begin{array}{r}-13,9 \% \\
32,6 \% \\
\end{array}$ & $\begin{array}{l}0,8 \% \\
3,2 \% \\
\end{array}$ & $\begin{array}{l}-1,9 \% \\
-0,1 \% \\
\end{array}$ & $\begin{array}{l}0,4 \% \\
4,0 \% \\
\end{array}$ & $\begin{array}{r}-0,3 \% \\
2,3 \% \\
\end{array}$ \\
\hline $\begin{array}{l}\text { Química básica e plásticos } \\
\text { Química de especialidades } \\
\text { Farmacêutica }\end{array}$ & $\begin{array}{l}176 \\
256 \\
324 \\
\end{array}$ & $\begin{array}{l}129 \\
177 \\
213\end{array}$ & $\begin{array}{l}149 \\
199 \\
241 \\
\end{array}$ & $\begin{array}{l}-31,5 \% \\
-39,8 \% \\
-45,8 \%\end{array}$ & $\begin{array}{l}-0,5 \% \\
-2,9 \% \\
-8,2 \% \\
\end{array}$ & $\begin{array}{r}-3,5 \% \\
-2,8 \% \\
3,2 \% \\
\end{array}$ & $\begin{array}{r}-0,6 \% \\
0,1 \% \\
-2,0 \% \\
\end{array}$ & $\begin{array}{l}-1,6 \% \\
-1,8 \% \\
-2,0 \% \\
\end{array}$ \\
\hline $\begin{array}{l}\text { Siderurgia e metalurgia básica } \\
\text { Tubulações, fundição e forjaria } \\
\text { Produtos de metal, ferramentas e bélico }\end{array}$ & $\begin{array}{r}311 \\
99 \\
108 \\
\end{array}$ & $\begin{array}{r}232 \\
68 \\
77 \\
\end{array}$ & $\begin{array}{r}321 \\
73 \\
87 \\
\end{array}$ & $\begin{array}{l}-24,7 \% \\
-41,8 \% \\
-36,0 \%\end{array}$ & $\begin{array}{r}6,4 \% \\
-0,3 \% \\
-0,5 \% \\
\end{array}$ & $\begin{array}{l}-2,3 \% \\
-6,0 \% \\
-5,2 \% \\
\end{array}$ & $\begin{array}{r}-3,1 \% \\
2,8 \% \\
2,1 \% \\
\end{array}$ & $\begin{array}{r}0,0 \% \\
-1,2 \% \\
-1,3 \% \\
\end{array}$ \\
\hline Máquinas e equipamentos & 101 & 96 & 91 & $-5,7 \%$ & $1,9 \%$ & $-3,6 \%$ & $3,9 \%$ & $0,7 \%$ \\
\hline $\begin{array}{l}\text { Eletrônica e informática } \\
\text { Comunicação, áudio, vídeo e ótica }\end{array}$ & $\begin{array}{l}41 \\
60\end{array}$ & $\begin{array}{r}86 \\
150\end{array}$ & $\begin{array}{l}61 \\
93\end{array}$ & $\begin{array}{l}73,6 \% \\
95,7 \%\end{array}$ & $\begin{array}{l}22,2 \% \\
13,7 \%\end{array}$ & $\begin{array}{l}-5,9 \% \\
-1,2 \%\end{array}$ & $\begin{array}{r}9,4 \% \\
13,0 \%\end{array}$ & $\begin{array}{l}7,8 \% \\
8,2 \%\end{array}$ \\
\hline $\begin{array}{l}\text { Material Elétrico } \\
\text { Eletrodomésticos } \\
\text { Equipamentos e materiais médicos }\end{array}$ & $\begin{array}{r}130 \\
188 \\
21 \\
\end{array}$ & $\begin{array}{r}102 \\
120 \\
84 \\
\end{array}$ & $\begin{array}{r}111 \\
144 \\
42 \\
\end{array}$ & $\begin{array}{l}-25,3 \% \\
-47,7 \% \\
151,4 \%\end{array}$ & $\begin{array}{r}5,2 \% \\
-0,4 \% \\
7,7 \% \\
\end{array}$ & $\begin{array}{r}-6,6 \% \\
-7,3 \% \\
7,8 \% \\
\end{array}$ & $\begin{array}{r}3,3 \% \\
2,3 \% \\
14,3 \% \\
\end{array}$ & $\begin{array}{r}0,4 \% \\
-1,9 \% \\
10,1 \% \\
\end{array}$ \\
\hline $\begin{array}{l}\text { Automotiva } \\
\text { Outros equipamentos de transporte } \\
\text { Naval } \\
\text { Aeroespacial }\end{array}$ & $\begin{array}{r}121 \\
76 \\
62 \\
122\end{array}$ & $\begin{array}{r}169 \\
139 \\
90 \\
214\end{array}$ & $\begin{array}{r}138 \\
112 \\
69 \\
218\end{array}$ & $\begin{array}{l}34,6 \% \\
55,8 \% \\
41,1 \% \\
42,1 \%\end{array}$ & $\begin{array}{r}3,6 \% \\
11,6 \% \\
6,3 \% \\
43,0 \% \\
\end{array}$ & $\begin{array}{r}0,4 \% \\
5,4 \% \\
7,6 \% \\
-14,4 \%\end{array}$ & $\begin{array}{l}4,7 \% \\
0,3 \% \\
2,4 \% \\
9,4 \%\end{array}$ & $\begin{array}{r}2,9 \% \\
5,4 \% \\
5,4 \% \\
10,9 \%\end{array}$ \\
\hline $\begin{array}{l}\text { Agroindústria animal e vegetal } \\
\text { Bebidas }\end{array}$ & $\begin{array}{l}112 \\
230\end{array}$ & $\begin{array}{r}95 \\
204\end{array}$ & $\begin{array}{r}99 \\
225\end{array}$ & $\begin{array}{l}-17,8 \% \\
-11,2 \%\end{array}$ & $\begin{array}{l}0,0 \% \\
5,5 \%\end{array}$ & $\begin{array}{l}-2,6 \% \\
-0,8 \%\end{array}$ & $\begin{array}{r}1,3 \% \\
-4,7 \%\end{array}$ & $\begin{array}{l}-0,4 \% \\
-0,3 \%\end{array}$ \\
\hline $\begin{array}{l}\text { Têxtil e vestuário } \\
\text { Couro e calçados } \\
\text { Diversos }\end{array}$ & $\begin{array}{l}28 \\
26 \\
81\end{array}$ & $\begin{array}{l}39 \\
39 \\
61 \\
\end{array}$ & $\begin{array}{l}32 \\
29 \\
63\end{array}$ & $\begin{array}{r}36,6 \% \\
41,9 \% \\
-31,0 \%\end{array}$ & $\begin{array}{r}4,7 \% \\
1,3 \% \\
-3,4 \% \\
\end{array}$ & $\begin{array}{r}0,7 \% \\
-1,6 \% \\
-3,1 \% \\
\end{array}$ & $\begin{array}{l}3,3 \% \\
8,6 \% \\
2,1 \%\end{array}$ & $\begin{array}{r}2,8 \% \\
2,8 \% \\
-1,3 \%\end{array}$ \\
\hline Total & 129 & 124 & 126 & $-3,9 \%$ & $2,2 \%$ & $-2,6 \%$ & $1,3 \%$ & $0,2 \%$ \\
\hline
\end{tabular}

Fonte: elaboração própria a partir de dados da PIA-IBGE

A análise da dinâmica intersetorial pode ser também refinada considerando-se como se distribuem os diferentes quartis de setores em termos do valor médio da Produtividade do setor para a média do período e da taxa de crescimento médio anual dessa Produtividade para a média do período 1996-2013. Neste sentido, a Tabela 8 apresenta informações sobre a distribuição de setores por diferentes quartis em termos do valor médio da produtividade do setor (na média do período 1996-2013) e da taxa de crescimento médio anual dessa produtividade (para a média anual do período 1996-2013). Para cada setor e para o conjunto do quartil correspondente são apresentadas informações para a média do período 19962013 referentes aos seguintes indicadores: i) valor médio produtividade do setor para o período; ii) taxa de crescimento médio anual da produtividade para o setor no período; iii) valor médio da participação no setor nos investimentos; iv) taxa de crescimento médio anual dos investimentos para o período; v) valor médio da participação no setor no total do VTI; vi) taxa de crescimento médio anual do VTI para o período.

No tocante à distribuição dos quartis por valor médio da Produtividade dos setores para o conjunto do período 1996-2013, identificam-se valores mais elevados para os setores de Petróleo e da Extrativa Ferrosos e Não ferrosos no $1^{\circ}$ quartil, que apresentava valores médios da Produtividade aproximadamente quatro vezes superior à média geral da indústria. Neste quartil, destaca-se também o maior dinamismo, em termos do crescimento da Produtividade nos setores Aeroespacial (principalmente) e de Extrativa Ferrosos e Não ferrosos. No entanto, esse quartil com maior valor da Produtividade apresentava, para a média anual do período, um crescimento anual da Produtividade de apenas 0,2\%, equivalente á média geral da indústria. O quartil de maior valor da Produtividade era responsável por 40,5\% do total do VTI e por $48,8 \%$ do total de Investimentos. Esse quartil destaca-se também pelo maior crescimento anual dos 
Investimentos, de 6,4\% ao ano, contra uma média geral de 4,5\%. No tocante aos demais quartis em termos do valor da Produtividade, cabe destacar, em especial, o $4^{\circ}$ quartil que, apesar de apresentar uma Produtividade equivalente a aproximadamente um quarto da média geral, era aquele no qual ocorrem maiores taxas de crescimento para esse indicador (de 2,7\% ao ano na média do período) e para o VTI (de 5,3\% ao ano). Esse maior crescimento da Produtividade em atividades com menor valor da mesma sugere, a princípio, para uma redução dos diferenciais de Produtividade entre os diferentes setores.

Já quando se considera a distribuição dos quartis por crescimento médio anual da Produtividade nos diferentes setores para o período 1996-2013, percebe-se o maior dinamismo dos setores de Equipamentos e materiais médicos, Equipamentos de Comunicação e Aeroespacial no $1^{\circ}$ quartil, que, no entanto, apresentava valores médios da Produtividade equivalentes a aproximadamente a metade da média geral da indústria. Esse quartil mais dinâmico em termos de crescimento da Produtividade também apresentava maiores taxas de crescimento do VTI, de 7,9\% ao ano e dos Investimentos, de 8,9\% ao ano (com destaque para os setores Aeroespacial e Naval). Por outro lado, esse quartil era responsável por apenas $4,8 \%$ do VTI e por 3,7\% dos Investimentos. No tocante aos demais quartis em termos do crescimento da Produtividade, cabe destacar, em especial, o $3^{\circ}$ quartil que, apesar de apresentar um crescimento médio anual negativo desse indicador de $-0,2 \%$ ao ano concentrava $51,6 \%$ do VTI e $62,8 \%$ dos Investimentos. Cabe mencionar também o comportamento extremamente negativo da evolução da Produtividade no quarto quartil, com queda de 2,0\% ao ano, com destaque negativo para os setores de Química básica e plásticos, Química de especialidades, Farmacêutica e Eletrodomésticos.

Tabela 8- Quartis de Setores por Valo da Produtividade (média 1996-2013) e Crescimento da Produtividade (média anual 1996-2013) - Valores Médios de Indicadores para o período 1996-2013

\begin{tabular}{|c|c|c|c|c|c|c|c|c|c|c|c|c|c|c|}
\hline & \multicolumn{6}{|c|}{ Produtividade - VTI por empregado (média 1996-2013) } & & \multicolumn{7}{|c|}{$\begin{array}{l}\text { Crescimento da Produtividade } \\
\text { (média anual 1996-2013) }\end{array}$} \\
\hline & $\begin{array}{c}\text { Valor } \\
\text { Produti } \\
\text { vidade }\end{array}$ & $\begin{array}{c}\text { Var } \\
\text { anual } \\
\text { Produti } \\
\text { vidade }\end{array}$ & $\begin{array}{l}\text { Valor } \\
\text { VTI }\end{array}$ & $\begin{array}{l}\text { Var } \\
\text { VTI }\end{array}$ & $\begin{array}{l}\text { Valor } \\
\text { Investi } \\
\text { mento } \\
\end{array}$ & $\begin{array}{l}\text { Var } \\
\text { Investi } \\
\text { mento }\end{array}$ & & $\begin{array}{c}\text { Var } \\
\text { Absolu } \\
\text { ta } \\
\text { Produ }\end{array}$ & $\begin{array}{c}\text { Var } \\
\text { Anual } \\
\text { Produt } \\
\text { ividau } \\
\text { de }\end{array}$ & $\begin{array}{c}\text { Valor } \\
\text { Produt } \\
\text { ividade }\end{array}$ & $\begin{array}{c}\text { Valor } \\
\text { VTI }\end{array}$ & $\begin{array}{l}\text { Var } \\
\text { VTI }\end{array}$ & $\begin{array}{l}\text { Valor } \\
\text { Investi } \\
\text { mento }\end{array}$ & $\begin{array}{l}\text { Var } \\
\text { Investi } \\
\text { mento }\end{array}$ \\
\hline Petróleo & 2.012 & $1,0 \%$ & $14,9 \%$ & $5,1 \%$ & $23,4 \%$ & $11,0 \%$ & Equip. e materiais médicos & $374,9 \%$ & $10,1 \%$ & 42 & $0,1 \%$ & $17,0 \%$ & $0,1 \%$ & $24,1 \%$ \\
\hline Extrativa - Ferrs e Não ferrosos & 1.175 & $2,0 \%$ & $6,2 \%$ & $7,0 \%$ & $10,1 \%$ & $15,8 \%$ & Eq. Comunicação, & $236,4 \%$ & $8,2 \%$ & 93 & $0,7 \%$ & $11,9 \%$ & $0,4 \%$ & $22,5 \%$ \\
\hline Siderurgia e metalurgia básica & 321 & $0,0 \%$ & $6,9 \%$ & $2,1 \%$ & $8,0 \%$ & $2,5 \%$ & Aeroespacial & $182,3 \%$ & $10,9 \%$ & 218 & $0,4 \%$ & $19,7 \%$ & $0,2 \%$ & $30,4 \%$ \\
\hline Farmacêutica & 241 & $-2,0 \%$ & $3,5 \%$ & $-0,2 \%$ & $1,5 \%$ & $1,2 \%$ & Eletrônica e informática & $144,3 \%$ & $7,8 \%$ & 61 & $0,3 \%$ & $12,8 \%$ & $0,3 \%$ & $7,6 \%$ \\
\hline Bebidas & 225 & $-0,3 \%$ & $3,6 \%$ & $2,6 \%$ & $3,1 \%$ & $14,4 \%$ & Outros eq. de transporte & $122,6 \%$ & $5,4 \%$ & 112 & $0,3 \%$ & $10,5 \%$ & $0,4 \%$ & $18,9 \%$ \\
\hline Aeroespacial & 218 & $10,9 \%$ & $0,4 \%$ & $19,7 \%$ & $0,2 \%$ & $30,4 \%$ & Naval & $81,0 \%$ & $5,4 \%$ & 69 & $0,1 \%$ & $18,4 \%$ & $0,2 \%$ & $90,6 \%$ \\
\hline Química de especialidades & 199 & $-1,8 \%$ & $4,9 \%$ & $1,1 \%$ & $2,5 \%$ & $3,3 \%$ & Têxtil e vestuário & $56,1 \%$ & $2,8 \%$ & 32 & $3,0 \%$ & $5,2 \%$ & $2,1 \%$ & $6,1 \%$ \\
\hline 10 Quartil & 475 & $0,2 \%$ & $40,5 \%$ & $3,1 \%$ & $48,8 \%$ & $6,4 \%$ & 10 Quartil & $113,3 \%$ & $4,8 \%$ & 47 & $4,8 \%$ & $7,9 \%$ & $3,7 \%$ & $8,7 \%$ \\
\hline Celulose e papel & 153 & $1,2 \%$ & $3,3 \%$ & $3,0 \%$ & $4,4 \%$ & $5,3 \%$ & Couro e calçados & $55,0 \%$ & $2,8 \%$ & 29 & $1,2 \%$ & $5,4 \%$ & $0,6 \%$ & $6,7 \%$ \\
\hline plásticos & 149 & $-1,6 \%$ & $9,2 \%$ & $1,3 \%$ & $7,6 \%$ & $3,0 \%$ & Automotiva & $52,8 \%$ & $2,9 \%$ & 138 & $5,7 \%$ & $6,4 \%$ & $7,3 \%$ & $10,6 \%$ \\
\hline Eletrodomésticc & 144 & $-1,9 \%$ & $1,2 \%$ & $0,1 \%$ & $1,1 \%$ & $69,8 \%$ & Madeira e móveis & $42,8 \%$ & $2,3 \%$ & 42 & $2,2 \%$ & $4,6 \%$ & $1,8 \%$ & $7,3 \%$ \\
\hline Automotiva & 138 & $2,9 \%$ & $5,7 \%$ & $6,4 \%$ & $7,3 \%$ & $10,6 \%$ & Celulose e papel & $17,8 \%$ & $1,2 \%$ & 153 & $3,3 \%$ & $3,0 \%$ & $4,4 \%$ & $5,3 \%$ \\
\hline Outros eq. de transporte & 112 & $5,4 \%$ & $0,3 \%$ & $10,5 \%$ & $0,4 \%$ & $18,9 \%$ & Máquinas e equipamentos ( & $5,8 \%$ & $0,7 \%$ & 91 & $4,2 \%$ & $6,2 \%$ & $2,5 \%$ & $7,0 \%$ \\
\hline Material Elétrico & 111 & $0,4 \%$ & $2,4 \%$ & $3,9 \%$ & $1,2 \%$ & $3,7 \%$ & Material Elétrico & $-3,1 \%$ & $0,4 \%$ & 111 & $2,4 \%$ & $3,9 \%$ & $1,2 \%$ & $3,7 \%$ \\
\hline 20 Quartil & 140 & $0,3 \%$ & $22,0 \%$ & $3,3 \%$ & $22,0 \%$ & $3,6 \%$ & 20 Quartil & $31,9 \%$ & $1,8 \%$ & 86 & $18,9 \%$ & $5,1 \%$ & $17,8 \%$ & $4,6 \%$ \\
\hline Agro-indústri & 99 & $-0,4 \%$ & $15,5 \%$ & $3,3 \%$ & $13,9 \%$ & $4,4 \%$ & Extrativa - Fer & $-6,3 \%$ & $2,0 \%$ & 1.175 & $6,2 \%$ & $7,0 \%$ & $10,1 \%$ & $15,8 \%$ \\
\hline Eq. Con & 93 & $8,2 \%$ & $0,7 \%$ & $11,9 \%$ & $0,4 \%$ & $22,5 \%$ & Petróleo & $-7,6 \%$ & $1,0 \%$ & 2.012 & $14,9 \%$ & $5,1 \%$ & $23,4 \%$ & $11,0 \%$ \\
\hline Máquinas e equipamentos & 91 & $0,7 \%$ & $4,2 \%$ & $6,2 \%$ & $2,5 \%$ & $7,0 \%$ & Extr. e Mat construção & $-9,8 \%$ & $-0,3 \%$ & 79 & $4,4 \%$ & $3,7 \%$ & $4,3 \%$ & $6,8 \%$ \\
\hline Produtos de metal & 87 & $-1,3 \%$ & $2,7 \%$ & $1,6 \%$ & $1,4 \%$ & $2,3 \%$ & Agro-indústria animal e vegetal & $-10,8 \%$ & $-0,4 \%$ & 99 & $15,5 \%$ & $3,3 \%$ & $13,9 \%$ & $4,4 \%$ \\
\hline Extr. e Mat constru & 79 & $-0,3 \%$ & $4,4 \%$ & $3,7 \%$ & $4,3 \%$ & $6,8 \%$ & Siderurgia e metalurgia básica & $-14,9 \%$ & $0,0 \%$ & 321 & $6,9 \%$ & $2,1 \%$ & $8,0 \%$ & $2,5 \%$ \\
\hline Tubulações, fundição e forjaria & 73 & $-1,2 \%$ & $2,3 \%$ & $3,4 \%$ & $1,2 \%$ & $7,2 \%$ & Bebidas & $-17,6 \%$ & $-0,3 \%$ & 225 & $3,6 \%$ & $2,6 \%$ & $3,1 \%$ & $14,4 \%$ \\
\hline 3o Quartil & 90 & $-0,2 \%$ & $29,9 \%$ & $3,8 \%$ & $23,8 \%$ & $3,9 \%$ & 3o Quartil & $-6,3 \%$ & $-0,2 \%$ & 198 & $51,6 \%$ & $3,5 \%$ & $62,8 \%$ & $5,7 \%$ \\
\hline Naval & 69 & $5,4 \%$ & $0,1 \%$ & $18,4 \%$ & $0,2 \%$ & $90,6 \%$ & Dive & $-22,8 \%$ & $-1,3 \%$ & 63 & $0,9 \%$ & $1,6 \%$ & $0,4 \%$ & $4,0 \%$ \\
\hline Diversos & 63 & $-1,3 \%$ & $0,9 \%$ & $1,6 \%$ & $0,4 \%$ & $4,0 \%$ & Produtos de metal & $-23,3 \%$ & $-1,3 \%$ & 87 & $2,7 \%$ & $1,6 \%$ & $1,4 \%$ & $2,3 \%$ \\
\hline Eletrônica e informática & 61 & $7,8 \%$ & $0,3 \%$ & $12,8 \%$ & $0,3 \%$ & $7,6 \%$ & Tubulações, fundição e forjaria & $-25,4 \%$ & $-1,2 \%$ & 73 & $2,3 \%$ & $3,4 \%$ & $1,2 \%$ & $7,2 \%$ \\
\hline Madeira e móveis & 42 & $2,3 \%$ & $2,2 \%$ & $4,6 \%$ & $1,8 \%$ & $7,3 \%$ & Química básica e plásticos & $-27,1 \%$ & $-1,6 \%$ & 149 & $9,2 \%$ & $1,3 \%$ & $7,6 \%$ & $3,0 \%$ \\
\hline Equip. médicos & 42 & $10,1 \%$ & $0,1 \%$ & $17,0 \%$ & $0,1 \%$ & $24,1 \%$ & Química de especialidades & $-29,4 \%$ & $-1,8 \%$ & 199 & $4,9 \%$ & $1,1 \%$ & $2,5 \%$ & $3,3 \%$ \\
\hline Têxtil e vestuário & 32 & $2,8 \%$ & $3,0 \%$ & $5,2 \%$ & $2,1 \%$ & $6,1 \%$ & Farmacêutica & $-35,7 \%$ & $-2,0 \%$ & 241 & $3,5 \%$ & $-0,2 \%$ & $1,5 \%$ & $1,2 \%$ \\
\hline Couro e calçados & 29 & $2,8 \%$ & $1,2 \%$ & $5,4 \%$ & $0,6 \%$ & $6,7 \%$ & Eletrodomésticos & $-38,3 \%$ & $-1,9 \%$ & 144 & $1,2 \%$ & $0,1 \%$ & $1,1 \%$ & $69,8 \%$ \\
\hline 4o Quartil & 38 & $2,7 \%$ & $7,7 \%$ & $5,3 \%$ & $5,5 \%$ & $5,6 \%$ & 4o Quartil & $-30,7 \%$ & $-2,0 \%$ & 128 & $24,7 \%$ & $1,0 \%$ & $15,7 \%$ & $2,9 \%$ \\
\hline Total & 126 & $0,2 \%$ & $100 \%$ & $3,4 \%$ & $100 \%$ & $4,5 \%$ & Total & $1,1 \%$ & $0,2 \%$ & 126 & $100 \%$ & $3,4 \%$ & $100 \%$ & $4,5 \%$ \\
\hline
\end{tabular}

Fonte: elaboração própria a partir de dados da PIA-IBGE

É possível complementar a análise da dinâmica intersetorial, considerando informações sobre o comportamento dos quartis com maior valor médio da Produtividade em relação à estrutura e ao dinamismo de diferentes indicadores para a média geral do período 1996-2013 e para média dos diversos subperíodos trienais considerados, conforme ilustrado pela Tabela 9. A partir dessas informações, algumas tendências interessantes podem ser destacadas. O quartil mais relevante em termos do valor da Produtividade apresentava taxas anuais de crescimento expressivas para esse indicador nos subperíodos 1996-1998 e 1999-2001, mas a partir daí essas taxas apresentam valores negativos expressivamente inferiores à média geral. Apesar do baixo dinamismo do crescimento da Produtividade nesse quartil, o mesmo apresenta taxas de crescimento dos Investimentos bastante expressivas nos períodos 2005-2007, 
2008-2010 e 2011-2013. Além disso, a participação desse quartil no total do VTI mantém-se na faixa de $40 \%$ ao longo dos subperíodos considerados, enquanto esse percentual para os Investimentos localiza-se na faixa de 50\%. O terceiro quartil em termos de valores da Produtividade, por sua vez, concentrava mais de $40 \%$ do emprego, apresentando um crescimento da Produtividade superior à média geral nos subperíodos 2008-2010 e 2011-2013. Dentre os demais quartis, cabe destacar o maior crescimento da Produtividade no quarto quartil, com menores valores da Produtividade, particularmente a partir de 20052007, o que aponta para uma "convergência" dos níveis intersetoriais de Produtividade no período mais recente.

Tabela 9- Indicadores por Quartis de Setores em termos do Valor da Produtividade e do Crescimento da Produtividade (média anual 1996-2013) - VTI (Estrutura e Crescimento), Emprego (Estrutura e Crescimento), Investimento (Estrutura e Crescimento) e Produtividade (Valor e Crescimento) - Média Geral 1996-2013 e Média para períodos trienais

\begin{tabular}{|c|c|c|c|c|c|c|c|c|c|c|c|c|c|c|}
\hline & \multicolumn{7}{|c|}{ Valor da Produtividade } & \multicolumn{7}{|c|}{ Crescimento da Produtividade } \\
\hline & Média & 1996-1998 & 1999-2001 & $2002-2004$ & 2005-2007 & 2008-2010 & $2011-2013$ & Média & 1996-1998 & 1999-2001 & $2002-2004$ & 2005-2007 & 2008-2010 & $2011-2013$ \\
\hline \multicolumn{15}{|c|}{ Produtividade(Valor e Crescimento) } \\
\hline 1o QUARTL & 475 & 441 & 567 & 519 & 485 & 445 & 429 & 47 & 33 & 44 & 42 & 43 & 50 & 60 \\
\hline 20 QUARTL & 140 & 147 & 150 & 141 & 126 & 138 & 143 & 86 & 83 & 82 & 81 & 76 & 89 & 99 \\
\hline 3o QUARTL & 90 & 104 & 98 & 89 & 83 & 83 & 90 & 198 & 197 & 236 & 213 & 198 & 181 & 182 \\
\hline 4o QUARTL & 38 & 33 & 36 & 35 & 34 & 40 & 47 & 128 & 167 & 151 & 129 & 114 & 112 & 114 \\
\hline Total & 126 & 129 & 138 & 126 & 118 & 118 & 124 & 126 & 129 & 138 & 126 & 118 & 118 & 124 \\
\hline 10 QUARTL & $0,2 \%$ & $5,7 \%$ & $5,6 \%$ & $-2,3 \%$ & $-3,2 \%$ & $-0,2 \%$ & $-2,9 \%$ & $4,8 \%$ & $10,2 \%$ & $10,5 \%$ & $-5,6 \%$ & $4,3 \%$ & $5,2 \%$ & $6,2 \%$ \\
\hline 20 QUARTL & $0,3 \%$ & $4,5 \%$ & $-0,4 \%$ & $-3,3 \%$ & $-1,4 \%$ & $3,7 \%$ & $0,2 \%$ & $1,8 \%$ & $6,7 \%$ & $-1,3 \%$ & $-2,3 \%$ & $0,5 \%$ & $6,3 \%$ & $2,6 \%$ \\
\hline 3o QUARTL & $-0,2 \%$ & $3,9 \%$ & $-1,8 \%$ & $-6,2 \%$ & $-0,2 \%$ & $2,0 \%$ & $2,3 \%$ & $-0,2 \%$ & $4,0 \%$ & $4,3 \%$ & $-4,2 \%$ & $-2,5 \%$ & $0,1 \%$ & $-1,3 \%$ \\
\hline 4o QUARTL & $2,7 \%$ & $4,5 \%$ & $2,7 \%$ & $-3,3 \%$ & $2,6 \%$ & $6,0 \%$ & $4,2 \%$ & $-2,0 \%$ & $1,3 \%$ & $-4,8 \%$ & $-5,9 \%$ & $-1,6 \%$ & $0,4 \%$ & $-0,4 \%$ \\
\hline Total & $0,2 \%$ & $4,6 \%$ & $0,6 \%$ & $-4,3 \%$ & $-0,9 \%$ & $1,9 \%$ & $0,7 \%$ & $0,2 \%$ & $4,6 \%$ & $0,6 \%$ & $-4,3 \%$ & $-0,9 \%$ & $1,9 \%$ & $0,7 \%$ \\
\hline \multicolumn{15}{|c|}{ Emprego (Estrutura e Crescimento) } \\
\hline 10 QUARTL & $10,3 \%$ & $11,0 \%$ & $10,5 \%$ & $10,1 \%$ & $10,1 \%$ & $10,1 \%$ & $10,4 \%$ & $16,6 \%$ & $16,5 \%$ & $16,8 \%$ & $16,6 \%$ & $16,9 \%$ & $16,7 \%$ & $16,6 \%$ \\
\hline 20 QUARTL & $19,4 \%$ & $20,2 \%$ & $19,3 \%$ & $19,3 \%$ & $19,5 \%$ & $19,3 \%$ & $19,1 \%$ & $30,5 \%$ & $30,4 \%$ & $31,0 \%$ & $32,0 \%$ & $30,3 \%$ & $29,9 \%$ & $30,5 \%$ \\
\hline 3o QUARTL & $41,7 \%$ & $39,8 \%$ & $39,3 \%$ & $39,6 \%$ & $41,6 \%$ & $43,4 \%$ & $44,3 \%$ & $32,9 \%$ & $32,5 \%$ & $31,4 \%$ & $31,5 \%$ & $32,9 \%$ & $33,6 \%$ & $32,9 \%$ \\
\hline 4o QUARTL & $28,5 \%$ & $29,0 \%$ & $30,8 \%$ & $31,0 \%$ & $28,8 \%$ & $27,3 \%$ & $26,2 \%$ & $20,0 \%$ & $20,6 \%$ & $20,8 \%$ & $19,9 \%$ & $19,9 \%$ & $19,7 \%$ & $20,0 \%$ \\
\hline Total & 6.305 .897 & 4.768 .516 & 5.014 .813 & 5.729 .236 & 6.546.597 & 7.511 .638 & 8.264 .582 & 6.305 .897 & 4.768 .516 & $\mathbf{5 . 0 1 4 . 8 1 3}$ & 5.729 .236 & 6.546 .597 & 7.511 .638 & 8.264 .582 \\
\hline 1o QUARTL & $3,1 \%$ & $-3,0 \%$ & $-1,2 \%$ & $2,4 \%$ & $2,8 \%$ & $0,3 \%$ & $4,4 \%$ & $2,9 \%$ & $-5,4 \%$ & $1,7 \%$ & $6,7 \%$ & $5,0 \%$ & $2,0 \%$ & $2,8 \%$ \\
\hline 20 QUARTL & $3,0 \%$ & $-3,5 \%$ & $-2,9 \%$ & $3,5 \%$ & $3,6 \%$ & $1,8 \%$ & $6,8 \%$ & $3,2 \%$ & $-2,6 \%$ & $0,1 \%$ & $5,8 \%$ & $5,9 \%$ & $3,8 \%$ & $6,4 \%$ \\
\hline 3o QUARTL & $4,0 \%$ & $-1,9 \%$ & $-0,6 \%$ & $3,2 \%$ & $4,9 \%$ & $2,9 \%$ & $4,3 \%$ & $3,7 \%$ & $-2,5 \%$ & $-0,9 \%$ & $2,0 \%$ & $3,8 \%$ & $2,9 \%$ & $4,9 \%$ \\
\hline 4o QUARTL & $2,6 \%$ & $-2,9 \%$ & $3,7 \%$ & $7,8 \%$ & $5,4 \%$ & $2,8 \%$ & $4,6 \%$ & $3,2 \%$ & $-0,5 \%$ & $0,4 \%$ & $4,8 \%$ & $3,4 \%$ & $-0,1 \%$ & $4,2 \%$ \\
\hline Total & $3,3 \%$ & $-2,6 \%$ & $0,1 \%$ & $4,5 \%$ & $4,6 \%$ & $2,4 \%$ & $4,9 \%$ & $3,3 \%$ & $-2,6 \%$ & $0,1 \%$ & $4,5 \%$ & $4,6 \%$ & $2,4 \%$ & $4,9 \%$ \\
\hline \multicolumn{15}{|c|}{ VTI (Estrutura e Crescimento) } \\
\hline 10 QUARTL & $39,4 \%$ & $37,7 \%$ & $43,2 \%$ & $41,7 \%$ & $41,5 \%$ & $37,9 \%$ & $36,0 \%$ & $6,2 \%$ & $4,3 \%$ & $5,4 \%$ & $5,6 \%$ & $6,1 \%$ & $7,1 \%$ & $7,8 \%$ \\
\hline 20 QUARTL & $21,8 \%$ & $23,0 \%$ & $20,9 \%$ & $21,7 \%$ & $20,9 \%$ & $22,4 \%$ & $22,0 \%$ & $21,0 \%$ & $19,5 \%$ & $18,3 \%$ & $20,7 \%$ & $19,5 \%$ & $22,6 \%$ & $23,6 \%$ \\
\hline 3o QUARTL & $30,1 \%$ & $31,9 \%$ & $27,8 \%$ & $28,0 \%$ & $29,5 \%$ & $30,5 \%$ & $32,2 \%$ & $52,3 \%$ & $49,5 \%$ & $53,6 \%$ & $53,3 \%$ & $55,2 \%$ & $51,7 \%$ & $50,5 \%$ \\
\hline 4o QUARTL & $8,7 \%$ & $7,4 \%$ & $8,0 \%$ & $8,6 \%$ & $8,2 \%$ & $9,2 \%$ & $9,8 \%$ & $20,5 \%$ & $26,7 \%$ & $22,7 \%$ & $20,4 \%$ & $19,2 \%$ & $18,6 \%$ & $18,1 \%$ \\
\hline Total & 786.014 .788 & 615.462 .886 & 694.004.248 & 720.388.669 & 772.322 .817 & 887.274.277 & 1.026 .635 .828 & 786.014 .788 & 615.462 .886 & 694.004.248 & 720.388.669 & 772.322 .817 & 887.274.277 & $\begin{array}{r}1.026 .635 .82 \\
8\end{array}$ \\
\hline 10 QUARTL & $3,1 \%$ & $2,5 \%$ & $13,6 \%$ & $14,1 \%$ & $2,3 \%$ & $-2,3 \%$ & $-1,6 \%$ & $7,9 \%$ & $4,0 \%$ & $11,4 \%$ & $16,2 \%$ & $14,9 \%$ & $6,2 \%$ & $-6,9 \%$ \\
\hline 20 QUARTL & $3,3 \%$ & $1,0 \%$ & $-1,8 \%$ & $1,9 \%$ & $2,6 \%$ & $3,2 \%$ & $2,5 \%$ & $5,1 \%$ & $4,0 \%$ & $-2,8 \%$ & $2,0 \%$ & $8,0 \%$ & $7,6 \%$ & $4,1 \%$ \\
\hline 3o QUARTL & $3,8 \%$ & $2,0 \%$ & $-2,4 \%$ & $-4,1 \%$ & $3,9 \%$ & $6,6 \%$ & $-2,2 \%$ & $3,5 \%$ & $1,4 \%$ & $9,4 \%$ & $10,4 \%$ & $3,2 \%$ & $0,4 \%$ & $-1,1 \%$ \\
\hline 4o QUARTL & $5,3 \%$ & $1,4 \%$ & $7,6 \%$ & $8,9 \%$ & $6,8 \%$ & $5,9 \%$ & $1,5 \%$ & $1,0 \%$ & $0,8 \%$ & $-0,2 \%$ & $-3,3 \%$ & $-3,9 \%$ & $-0,7 \%$ & $-2,1 \%$ \\
\hline Total & $3,4 \%$ & $1,8 \%$ & $4,5 \%$ & $5,5 \%$ & $2,9 \%$ & $1,8 \%$ & $-0,6 \%$ & $3,4 \%$ & $1,8 \%$ & $4,5 \%$ & $5,5 \%$ & $2,9 \%$ & $1,8 \%$ & $-0,6 \%$ \\
\hline \multicolumn{15}{|c|}{ Investimento (Estrutura e Crescimento) } \\
\hline 10 QUARTL & $49,6 \%$ & $40,2 \%$ & $42,7 \%$ & $54,1 \%$ & $51,3 \%$ & $50,7 \%$ & $53,7 \%$ & $3,7 \%$ & $3,2 \%$ & $4,5 \%$ & $3,3 \%$ & $3,2 \%$ & $4,2 \%$ & $3,8 \%$ \\
\hline 20 QUARTL & $21,2 \%$ & $29,6 \%$ & $26,4 \%$ & $20,4 \%$ & $18,9 \%$ & $18,4 \%$ & $18,0 \%$ & $17,3 \%$ & $19,1 \%$ & $22,4 \%$ & $17,9 \%$ & $15,9 \%$ & $15,1 \%$ & $16,3 \%$ \\
\hline 3o QUARTL & $23,9 \%$ & $24,5 \%$ & $24,3 \%$ & $20,1 \%$ & $25,2 \%$ & $25,6 \%$ & $23,3 \%$ & $64,0 \%$ & $54,1 \%$ & $54,4 \%$ & $64,1 \%$ & $68,1 \%$ & $68,1 \%$ & $68,1 \%$ \\
\hline 4o QUARTL & $5,4 \%$ & $5,8 \%$ & $6,6 \%$ & $5,5 \%$ & $4,6 \%$ & $5,3 \%$ & $5,0 \%$ & $15,0 \%$ & $23,7 \%$ & $18,7 \%$ & $14,6 \%$ & $12,8 \%$ & $12,6 \%$ & $11,9 \%$ \\
\hline Total & 136.634 .479 & 109.765 .245 & 101.939 .737 & 113.248 .735 & 134.913 .888 & 163.905 .960 & 196.033 .310 & 136.634 .479 & 109.765 .245 & 101.939 .737 & 113.248 .735 & 134.913 .888 & 163.905 .960 & 196.033 .310 \\
\hline 1o QUARTL & $6,4 \%$ & $-3,0 \%$ & $-0,4 \%$ & $-5,1 \%$ & $7,8 \%$ & $27,2 \%$ & $17,2 \%$ & $8,7 \%$ & $15,2 \%$ & $6,0 \%$ & $-0,7 \%$ & $26,9 \%$ & $6,5 \%$ & $-19,6 \%$ \\
\hline 20 QUARTL & $3,6 \%$ & $14,6 \%$ & $-2,9 \%$ & $-18,8 \%$ & $9,3 \%$ & $7,8 \%$ & $-16,6 \%$ & $4,6 \%$ & $-4,9 \%$ & $6,1 \%$ & $-1,6 \%$ & $13,4 \%$ & $14,9 \%$ & $-18,0 \%$ \\
\hline 30 QUARTL & $3,9 \%$ & $-3,9 \%$ & $-5,0 \%$ & $-0,5 \%$ & $-1,9 \%$ & $-1,2 \%$ & $-7,8 \%$ & $5,7 \%$ & $-5,2 \%$ & $-5,2 \%$ & $-3,4 \%$ & $5,8 \%$ & $19,9 \%$ & $12,3 \%$ \\
\hline 4o QUARTL & $5,6 \%$ & $23,1 \%$ & $3,3 \%$ & $-8,7 \%$ & $13,2 \%$ & $4,5 \%$ & $-12,6 \%$ & $2,9 \%$ & $31,7 \%$ & $-0,4 \%$ & $-23,8 \%$ & $-6,1 \%$ & $-2,3 \%$ & $-2,6 \%$ \\
\hline Total & $4,5 \%$ & $3,0 \%$ & $-3,1 \%$ & $-9,0 \%$ & $5,8 \%$ & $13,4 \%$ & $1,4 \%$ & $4,5 \%$ & $\mathbf{3 , 0} \%$ & $-3,1 \%$ & $-9,0 \%$ & $5,8 \%$ & $13,4 \%$ & $1,4 \%$ \\
\hline
\end{tabular}

Fonte: elaboração própria a partir de dados da PIA-IBGE

A Tabela 9 também apresenta informações sobre o comportamento dos quartis com maior crescimento médio anual da Produtividade em relação à estrutura e ao dinamismo de indicadores para a média geral do período 1996-2013 e para média dos diversos subperíodos trienais considerados. Com base nestas informações, algumas tendências importantes também podem ser destacadas. Com base nestas informações, verifica-se que o quartil mais dinâmico em termos do crescimento da Produtividade, além de valores absolutos mais baixos para o indicador, tem mantido um peso limitado no total do Emprego, do VTI e dos Investimentos. No entanto, se a Produtividade absoluta desse quartil equivalia a aproximadamente um quarto da média geral em 1996-1998, esse percentual se eleva a quase $50 \%$ em 2011-2013. Dentre os demais quartis, cabe destacar o peso do terceiro quartil que, apesar de apresentar um crescimento medíocre da produtividade a partir de 2002-2004, apresenta valores absolutos mais elevados para o indicador continuou concentrando mais de $50 \%$ do VTI e quase $70 \%$ do total de Investimentos ao longo dos subperíodos mais recentes. 
Considerando o comportamento da Produtividade e de outros indicadores (Salário Médio por empregado e Receita Média por Empresa), é possível avaliar como se comportam os diferenciais intersetoriais dessas medidas, que poderiam revelar a existência de uma maior ou menor "heterogeneidade intersetorial", quando medidos em um instante particular no tempo. Além disso, é também possível avaliar o processo de "convergência" desses indicadores ao longo do tempo, comparando-se os diferenciais de crescimento dos mesmos entre diferentes setores. Esses aspectos são contemplados avaliando-se, para os indicadores selecionados, as correspondentes medidas de dispersão (desvio padrão) intersetorial de seus valores, calculados a partir de valores deflacionados; Estes indicadores podem ser utilizados tanto para captar a desvio das participações entre setores, refletindo a heterogeneidade da estrutura industrial, como para captar o desvio das taxas de crescimento entre setores ao longo de diversos períodos, o que poderia evidenciar processos de convergência da dinâmica intersetorial.

A existência de uma maior ou menor "heterogeneidade intersetorial" pode ser avaliada a partir da evolução do desvio-padrão intersetorial para indicadores de Produtividade, Salário Médio e Tamanho em Termos de Receita por Empresa para diferentes subperíodos, o que forneceria indícios sobre a trajetória da indústria. Neste sentido, a Tabela 10 e o Gráficos 7 apresentam a evolução do desvio-padrão da participação de setores para esses indicadores para diferentes subperíodos. As informações apresentadas revelam uma trajetória de redução da "heterogeneidade intersetorial" no tocante ao comportamento dos indicadores, que é mais evidente no caso da Produtividade, a partir de 2000.

Tabela 10 - Evolução do Desvio-Padrão Intersetorial para Indicadores de Produtividade, Salário Médio e Tamanho em Termos de Receita por Empresa para diferentes subperíodos

\begin{tabular}{|c|c|c|c|c|c|c|}
\hline & $\begin{array}{c}\text { PRODUTIVID } \\
\text { ADE }\end{array}$ & $\begin{array}{c}\text { PRODUTIVID } \\
\text { ADE (1996 = } \\
100)\end{array}$ & $\begin{array}{c}\text { SALARIO } \\
\text { MEDIO } \\
\end{array}$ & $\begin{array}{c}\text { SALARIO } \\
\text { MEDIO (1996 = } \\
100)\end{array}$ & $\begin{array}{l}\text { TAMANHO } \\
\text { RECEITA }\end{array}$ & $\begin{array}{c}\text { TAMANHO } \\
\text { RECEITA } \\
(1996=100) \\
\end{array}$ \\
\hline \multicolumn{7}{|c|}{ Períodos Trianuais } \\
\hline 1996-1998 & 347 & 104 & 76 & 95 & 571.357 & $\overline{79}$ \\
\hline 1999-2001 & 613 & 184 & 49 & 62 & 547.615 & 76 \\
\hline 2002-2004 & 513 & 154 & 37 & 46 & 380.172 & 53 \\
\hline 2005-2007 & 431 & 130 & 29 & 36 & 348.643 & 48 \\
\hline 2008-2010 & 338 & 102 & 28 & 36 & 280.268 & 39 \\
\hline 2011-2013 & 309 & 93 & 30 & 38 & 245.496 & 34 \\
\hline Var índice & $-11,0 \%$ & $-11,0 \%$ & $-60,5 \%$ & $-60,5 \%$ & $-57,0 \%$ & $-57,0 \%$ \\
\hline \multicolumn{7}{|c|}{ Períodos de Seis anos } \\
\hline 1996-2001 & 478 & 144 & 63 & 78 & 559.143 & 77 \\
\hline 2002-2007 & 471 & 142 & 32 & 41 & 364.396 & 50 \\
\hline 2008-2013 & 324 & 97 & 29 & 36 & 262.837 & 36 \\
\hline Var índice & $-32,3 \%$ & $-32,3 \%$ & $-53,5 \%$ & $-53,5 \%$ & $-53,0 \%$ & $-53,0 \%$ \\
\hline
\end{tabular}

Fonte: elaboração própria a partir de dados da PIA-IBGE

\section{Gráfico 7 - Evolução do Desvio-Padrão Intersetorial para Indicadores de Produtividade, Salário Médio e Tamanho em Termos de Receita por Empresa para o período 1996-2013}

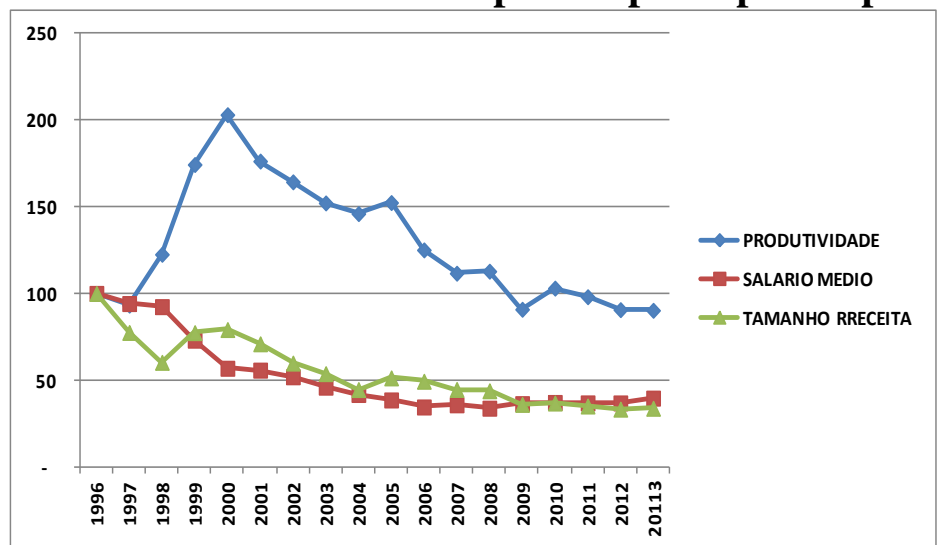

Fonte: elaboração própria a partir de dados da PIA-IBGE

Procurou-se também considerar a evolução dos diferenciais intersetoriais em termos do crescimento da Produtividade, Salário Médio e Tamanho em Termos de Receita por Empresa - em valores deflacionados - ao longo de diferentes subperíodos, que permitiriam avaliar o processo de 
"convergência" entre os diferentes setores ao longo do tempo. Neste sentido, a Tabela 11 e o Gráfico 8 apresentam informações sobre o desvio padrão das taxas de crescimento intersetoriais para indicadores de Produtividade, Salário Médio e Tamanho em Termos de Receita por Empresa, considerando a média geral anual para o período 1996-2013 e as médias anuais para os diferentes subperíodos. No caso do Salário Médio, não há evidências que estaria ocorrendo uma convergência intersetorial das taxas de crescimento, podendo-se observar um aumento desses diferenciais entre 2007 e 2010, acompanhado pela redução dos mesmos entre 2010 e 2013. No caso do Tamanho em Termos de Receita por Empresa verifica-se um comportamento mais errático do indicador, mas com aparente redução dos diferenciais das taxas de crescimento intersetoriais a partir de 2008. Por fim, no caso da evolução da Produtividade, há evidências mais sólidas de uma tendência de redução dos diferenciais das taxas de crescimento intersetoriais, o que revelaria uma aparente "convergência" entre os diferentes setores ao longo do tempo no tocante ao crescimento daquele indicador.

Tabela 11 - Desvio Padrão das Taxas de Crescimento Intersetoriais para Indicadores de Produtividade, Salário Médio e Tamanho em Termos de Receita por Empresa - Média geral anual (1996-2013) e Médias Anuais para Subperíodos

\begin{tabular}{|c|c|c|c|c|c|c|c|c|}
\hline & $\begin{array}{l}\text { Média } \\
\text { Anual }\end{array}$ & $\begin{array}{c}1996- \\
1998 \\
\end{array}$ & $\begin{array}{c}1999 . \\
2001\end{array}$ & $\begin{array}{c}2002- \\
2004 \\
\end{array}$ & $\begin{array}{c}2005- \\
2007 \\
\end{array}$ & $\begin{array}{c}2008- \\
2010 \\
\end{array}$ & $\begin{array}{c}2011- \\
2013 \\
\end{array}$ & $\begin{array}{c}\text { Média } \\
\text { Sub- } \\
\text { periodos }\end{array}$ \\
\hline Produtividade & $3,8 \%$ & $10,2 \%$ & $12,4 \%$ & $5,6 \%$ & $6,9 \%$ & $5,7 \%$ & $5,9 \%$ & $7,8 \%$ \\
\hline Salário Médio & $4,1 \%$ & $6,0 \%$ & $6,6 \%$ & $5,6 \%$ & $5,2 \%$ & $6,4 \%$ & $5,8 \%$ & $5,9 \%$ \\
\hline Tamanho - Receita & $6,9 \%$ & $19,0 \%$ & $12,0 \%$ & $12,8 \%$ & $6,6 \%$ & $7,8 \%$ & $7,3 \%$ & $10,9 \%$ \\
\hline
\end{tabular}

Fonte: elaboração própria a partir de dados da PIA-IBGE

Gráfico8 - Desvio Padrão das Taxas de Crescimento Intersetoriais para Indicadores de Produtividade, Salário Médio e Tamanho em Termos de Receita por Empresa para o período 19962013

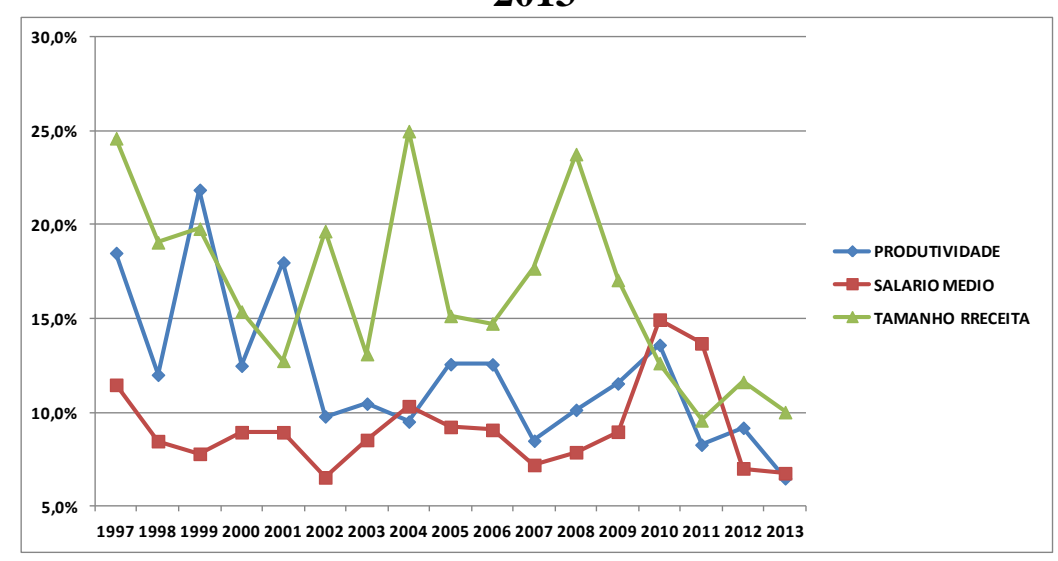

\section{Considerações Finais}

O estudo realizado apresenta evidências empíricas capazes de subsidiar o debate sobre a evolução da trajetória recente da indústria brasileira, a partir de um enfoque de tradição estruturalista, utilizando como base informações extraídas da PIA-IBGE para o período 1996-2013, ao longo do qual ocorreram transformações importantes no cenário interno e externo, com reflexos importantes na dinâmica de transformação produtiva e no desempenho da indústria brasileira.A evolução comparada da Produtividade do Trabalho e dos Salários Médios na indústria permite discutir e qualificar os argumentos da literatura sobre aspectos particulares da trajetória recente da indústria brasileira. Em primeiro lugar, mesmo constatando-se o baixo crescimento da Produtividade na média do período investigado ( $0,2 \%$ ao ano), verifica-se que, ao longo desse mesmo período, o crescimento do Salário Médio foi negativo (-0,8\% ao ano). Nesse sentido, o argumento sobre uma "tendência" de crescimento do Salário Médio acima da Produtividade do trabalho dificilmente se sustenta com base nos dados apresentados, fazendo com que a possibilidade de profit-squeeze vinculado aos custos salariais não se sustente como tendência geral, apesar assumir alguma relevância para explicar características dos períodos mais recentes. 
No tocante à realização de Investimentos, as informações apresentadas sugerem que uma eventual hipótese de estagnação da indústria em função da retração tendencial dos mesmos - que poderia justificar o argumento a favor do processo de desindustrialização - não encontra fundamento nas informações apresentadas. Pelo contrário, há indícios de que o Investimento na indústria brasileira apresenta uma tendência de crescimento entre 2004-2012, com correspondente elevação da Taxa de Investimento medida pela relação entre Investimento e VTI. Neste sentido, a questão-chave refere-se à "qualidade" desses investimentos. Em particular, verifica-se que a aceleração dos investimentos no período pós-2004 ocorreu à revelia de um crescimento da produtividade, que permaneceu relativamente estagnada durante aquele período. Provavelmente, essa tendência indica que as atividades que sustentaram esses investimentos não foram capazes de promover um aumento generalizado da produtividade na indústria, podendo-se sugerir que uma parcela desse impacto "vazou" para fora da indústria, seja na forma da aquisição de serviços e/ou de importações. Essa tendência pode ser captada pela forte "aderência" observada entre o crescimento dos Investimentos e o crescimento dos Serviços industriais prestados por terceiros.

Além disso, seguindo a literatura de tradição estruturalista, procurou-se qualificar a trajetória evolutiva da indústria, seus limites e fontes de dinamismo, bem como das transformações estruturais subjacentes às mesmas, a partir de um foco sobre a configuração intersetorial da indústria, utilizando-se para isso um recorte setorial abrangente que distingue 26 setores, agregando indústria extrativa e de transformação. No caso da evolução da Produtividade, para a média do período, maiores valores são observados nos setores de Petróleo; Extrativa - Ferrosos e Não ferrosos; Siderurgia e metalurgia básica; Farmacêutica; Bebidas. Em contraste, menores valores médios da Produtividade são observados nos setores de Couro e calçados; Têxtil e vestuário; Madeira e móveis; Equipamentos e materiais médicos. Além disso, apesar do baixo crescimento geral da Produtividade anual para o conjunto da indústria no período (de apenas 0,2\% ao ano), oito setores podem ser destacados por apresentarem uma taxa de crescimento médio da Produtividade mais elevada: Aeroespacial; Equipamentos e materiais médicos; Comunicação, áudio, vídeo e ótica; Eletrônica e informática; Outros equipamentos de transporte; Naval; Automotiva. Cabe destacar também a correlação positiva existente entre a distribuição setorial de maiores valores da Produtividade e maiores valores de outras variáveis, como os Investimentos, Receitas Financeiras, VTI e Lucros Totais. A avaliação da dinâmica intersetorial da produtividade revela tendências importantes. Em especial, observa-se que quartil com maior valor da Produtividade apresentava, para a média anual do período, um crescimento anual da Produtividade de apenas $0,2 \%$, equivalente à média geral da indústria. Esse quartil era responsável por 40,5\% do total do VTI e por $48,8 \%$ do total de Investimentos e se destacava pelo maior crescimento anual dos Investimentos, de $6,4 \%$ ao ano, contra uma média geral de $4,5 \%$. No tocante aos demais quartis em termos do valor da Produtividade, cabe destacar, em especial, o $4^{\circ}$ quartil que, apesar de apresentar uma Produtividade equivalente a aproximadamente um quarto da média geral, era aquele no qual ocorrem maiores taxas de crescimento para esse indicador (de 2,7\% ao ano na média do período) e para o VTI (de 5,3\% ao ano). Esse maior crescimento da Produtividade em atividades com menor valor da mesma sugere, a princípio, para uma redução dos diferenciais de Produtividade entre os diferentes setores.

A existência de uma maior ou menor "heterogeneidade intersetorial" foi também avaliada a partir da evolução do desvio-padrão intersetorial para diferentes indicadores. Com base na análise conjunta desses indicadores, verifica-se que a tendência de "convergência" intersetorial pode ser encontrada no caso da Produtividade, aos Salários Médios e ao Porte Empresarial. Assim, as informações apresentadas sugerem uma trajetória de redução da "heterogeneidade intersetorial" no tocante ao comportamento dos indicadores, que mais evidente no caso da Produtividade, a partir de 2000. A redução da dispersão das taxas de crescimento setoriais é mais evidente no caso da Receita Média por Estabelecimento, comparativamente à evolução do porte em termos do Número de Empregados. No caso do Salário Médio, essa dispersão apresenta-se relativamente estável ao longo dos subperíodos. Já no caso da Produtividade, observa-se uma tendência à redução da dispersão das taxas de crescimento entre os setores.Entretanto, mesmo nesse caso, a "convergência" se dá no contexto de uma trajetória de baixo dinamismo. Desse modo, aparentes sinais de redução da "heterogeneidade estrutural" da indústria brasileira devem ser vistos com cautela, pois não há evidências de que uma retomada sustentável de investimentos, ou um 
aprofundamento dos "ajustes produtivos" realizados pela indústria contribuiria para reforçar ou para reduzir essa convergência.

Por fim uma pequena nota quanto ao futuro. Obviamente, as tendências analisadas referem-se especificamente ao período contemplado pela PIA (1996-2013) e não captam os impactos da intensa crise enfrentada pela indústria brasileira no período 2014-2015, marcado por taxas negativas de crescimento, num contexto macroeconômico recessivo. No entanto, apesar dessas vicissitudes, é possível argumentar que a trajetória descrita revela tendências de ajustamento e aspectos relevantes da dinâmica intersetorial que tendem a persistir - ou mesmo a se intensificar - apesar do contexto circunstancialmente adverso, revelando oportunidades para uma retomada do crescimento da indústria em bases mais sustentáveis no longo prazo. A dinâmica cíclica da indústria tende a ser modulada em função dessas tendências e é a partir delas que perspectivas de mudança estrutural na direção de uma indústria com maior potencial de crescimento podem vir a ser vislumbradas.

\section{Referências}

ARBACHE, J. (2014). Serviços e Competitividade da Indústria Brasileira, Brasília: Confederação Nacional da Indústria.

ARBACHE, J. (2012). Is Brazilian Manufacturing Losing its Drive?, mimeo, Departamento de Economia, Universidade de Brasília,

BIELSCHOWSKY, R. "Estratégia de desenvolvimento e as três frentes de expansão no Brasil: um desenho conceitual”, Economia e Sociedade, Campinas, v. 21, Número Especial, p. 729-747, dez. 2012.

BONELLI, R. e PINHEIRO, A.C. "Competitividade e Desempenho Industrial: Mais que Só o Câmbio", Estudos e Pesquisas No 432, XXIV Fórum Nacional, Rio de Janeiro, 14 a 17 de maio de 2012

BONELLI, R. "Investimento nos setores industriais brasileiros: determinantes microeconômicos e requisitos para o crescimento / Regis. Brasília, DF: CEPAL. Escritório no Brasil/IPEA, Textos para Discussão CEPAL-IPEA, 38, 2011.

BONELLI, R.; BACHA, E. L. Crescimento brasileiro revisitado. In: VELOSO, F. et al. Desenvolvimento econômico: uma perspectiva brasileira. Rio de Janeiro: Elsevier, 2013.

BONELLI, R.; FONTES, Júlia. O desafio brasileiro no longo prazo. Ensaios IBRE de Economia Brasileira, n. 1, Rio de Janeiro, 2013.

CAVALCANTE, L.R.,..DE NEGRI, F. "Evolução Recente dos Indicadores de Produtividade no Brasil”, in De Negri, F., Cavalcante, L.R.. (org) "Produtividade no Brasil: desempenho e determinantes:" - Brasília : ABDI : IPEA, 445 p, 2014

DE NEGRI, F., CAVALCANTE, L.R.. (org) "Produtividade no Brasil: desempenho e determinantes:” - Brasília : ABDI : IPEA, 445 p, 2014.

DE NEGRI, F., CAVALCANTE, L.R.. "Os Dilemas e os Desafios da Produtividade no Brasil", in: De Negri, F., Cavalcante, L.R.. (org) "Produtividade no Brasil: desempenho e determinantes:" - Brasília : ABDI : IPEA, 445 p, 2014.

FEIJÓ, C. ; GALEANO, E. “A estagnação da produtividade do trabalho na indústria brasileira nos anos 1996-2007: análise nacional, regional e setorial”, Nova Economia, Belo Horizonte_23 (1)_9-50_Janeiro-abril de 2013

FEIJÓ, C. ; LAMONICA, M.T "Mudança Estrutural e Crescimento: consequências da política econômica de estabilização para o desempenho da economia brasileira nos anos 1990 e 2000", A Economia Brasileira na Encruzilhada, Associação Keynesiana Brasileira, Outubro de 2013

FEIJÓ, C.A. ; CARVALHO, P.G. M.; ALMEIDA, J. S. G.. Ocorreu uma desindustrialização no Brasil? São Paulo: Instituto de Estudos para o Desenvolvimento Industrial, nov. 2005.

Ferreira, P. C.; Ellery Junior, R. e Gomes, V. "Produtividade Agregada Brasileira (1970-2000): Declínio Robusto e Fraca Recuperação". Estudos Econômicos, v. 38, n. 1, pp. 31 - 53, 2008.

KUPFER, D. “Industrialização e Desindustrialização no Brasil: Muito Além dos Números”, GIC-IE/UFRJ e BNDES - 28o. Fórum de Debates Brasiliana. São Paulo, 23.08.2012 
LAMONICA, M. T.; FEIJÓ, C. A. Indústria de transformação e crescimento: uma interpretação para o desempenho da economia brasileira nos anos 1990 e 2000. Revista Economia \& Tecnologia, Curitiba, v. 9, n. 1, p. 20-40, jan./mar. 2013.

MIGUEZ, T.; MORAES, T. Produtividade do trabalho e mudança estrutural: uma comparação internacional com base no world input-output database (WIOD) 1995-2009. In: DE NEGRI, F.; CAVALCANTE, L. R. Produtividade no Brasil: desempenho e determinantes. Brasília: ABDI / IPEA, 2014

MORCEIRO, P.C. "desindustrialização na economia brasileira no período 2000-2011: abordagens e indicadores", Dissertação de Mestrado, Programa de Pós-Graduação em Economia, da Faculdade de Ciências e Letras Unesp/Araraquara, 2012

MOREIRA, R.F.C “Descentralização da Produção e Produtividade no Brasi”, Dissertação de Mestrado, Departamento de Economia da Universidade de Brasília, BRASÍLIA, 2015

NASSIF, A.; FEIJÓ, C.; ARAÚJO, E. "What determined labour productivity in the Brazilian manufacturing industries in the 2000s?", July 2014

NASSIF, A.; FEIJÓ, C.; ARAÚJO, E. The long- -term "optimal" real exchange rate and the currency overvaluation trend in open emerging economies: the case of Brazil. Geneva: UNCTAD, 2011. (Discussion Paper, n. 206).

PAULI, R.C.; NAKABASHI, L.; SAMPAIO, A.V.. Mudança estrutural e mercado de trabalho no Brasil. Rev. Econ. Polit., São Paulo , v. 32, n. 3, set. 2012 .

SAMPAIO, A. V.; PORCILE, G.; CURADO, M. Produtividade total dos fatores: aspectos teóricos e evidências brasileiras. Economia e tecnologia, ano 1, v. 3, set./dez. 2005.

SARTI, F.; HIRATUKA, C. Desenvolvimento industrial no Brasil: oportunidades e desafios futuros. Campinas: IE/UNICAMP, 2011. (Texto para Discussão, n. 187).

SILVA, J. A. A Questão da Desindustrialização no Brasil. Revista Economia \& Tecnologia, Curitiba, v. 10, n. 1, p. 45-75, jan./mar. 2014.

SILVA, J.A.; LOURENÇO, A.L.C "Desindustrialização em debate: teses e equívocos no caso da economia brasileira", Indic. Econ. FEE, Porto Alegre, v. 42, n.1, p. 57-76, 2014

SQUEFF, G. C. "Desindustrialização: luzes e sombras no debate brasileiro", Texto para Discussão 1747 - IPEA Brasília, DF, 56 p, ago. 2012

SQUEFF, G. C. Desindustrialização em debate: aspectos teóricos e alguns fatos estilizados da economia brasileira. Radar, Brasília, DF, n. 21, p. 7--17, ago. 2012

SQUEFF, G.C.; ARAÚJO, V.L. Trajetória da taxa de câmbio e heterogeneidade estrutural na indústria brasileira/ Brasília, DF: CEPAL. Escritório no Brasil/IPEA, (Textos para Discussão CEPAL-IPEA, 50, 62p., 2013.

TORRES, R. L.; KUPFER, D. Desindustrialização, uma ameaça real. In: SEMINÁRIO DE ECONOMIA INDUSTRIAL, 12., 2011, Araraquara. Anais... Araraquara: UNESP/GEEIN, 2011. p. 239-271.

TORRES, R.L. E SILVA, H.C "Uma crítica aos indicadores usuais de desindustrialização no Brasil”, Anais do $40^{\circ}$ Encontro Nacional de Economia. Porto de galinhas - Pernambuco, 2012 